\title{
Short Circuit Analysis of an Offshore AC Network having Multiple Grid Forming VSC-HVDC Links
}

\author{
Muhammad Raza ${ }^{\mathrm{a}, *}$, Mònica Aragüés Peñalba ${ }^{\mathrm{a}}$, Oriol Gomis-Bellmunt ${ }^{\mathrm{a}}$ \\ ${ }^{a}$ Centre d'Innovació Tecnològica en Convertidors Estàtics i Accionaments, Departament \\ d'Enginyeria Elèctrica, Universitat Politècnica de Catalunya, Barcelona Spain
}

\begin{abstract}
This article presents the short circuit analysis of an offshore AC network which consists of wind power plants interconnected using HVAC cables. The power generated in the offshore $\mathrm{AC}$ network is transmitted to several onshore grids using VSC-HVDC system. The offshore AC network is formed by the VSC-HVDC systems using frequency and voltage droop control. A coordinated control scheme is proposed for wind turbines and offshore VSCs during short circuit conditions in the offshore grid to ensure fault ride through (FRT) without compromising the system stability. The theoretical analysis used for developing this control scheme allows to calculate the system limits taking into consideration the active and reactive power capability. In order to verify the proposed control scheme, three phase symmetric faults have been applied on a wind turbine busbar, HVAC busbar, and at the AC cable that interconnects the VSC-HVDC system. Additionally, a frequency coordination control scheme without communication between wind power generation and VSC-HVDC system has been proposed. The methodology and control system have been validated by performing a nonlinear simulation.
\end{abstract}

Keywords: Frequency coordinated control, multiple VSCs offshore network, short circuit analysis, and wind energy.

\footnotetext{
* Corresponding author

Email addresses: muhammad.raza@citcea.upc.edu (Muhammad Raza), monica.aragues@citcea.upc.edu (Mònica Aragüés Peñalba), oriol.gomis@citcea.upc.edu (Oriol Gomis-Bellmunt)
} 


\section{Introduction}

Offshore AC networks, formed by interconnecting several wind power plants through medium or high voltage alternating current (MVAC/HVAC) cables, will be an essential part of the electrical system that will allow the integration of future large offshore wind power plants with the onshore grids [1]. High voltage direct current (HVDC) transmission systems based on voltage source converters (VSC) are suitable to transfer the power from offshore AC network located far from shore, and they have the ability to create an isolated network [2]. A voltage source converter in grid-forming control mode imposes the frequency on the network and controls the voltage ergo the VSC designated in the network as a reference machine. Nowadays, permanent magnet synchronous generator with fully rated converters are being installed in the offshore wind power plants and offshore network posses mainly power electronics devices. The dynamic characteristic of offshore network is very different from conventional grids and governed by converters. This make the network inertial-less and the short circuit capability of the converter is equal to the nominal current $[3,4]$.

As the wind power generation capacity increases, transmission system operators requires that the large offshore wind power plants should also behave like conventional generator and provides support to network frequency, reactive power support, and fault-ride-through (FRT) [5]. Among all grid code requirements, FRT is the most critical since wind power plant connected VSC-HVDC transmission system behavior is highly nonlinear during fault period and it weaken the system dynamic [6]. There are several studies conducted on the behavior of wind turbines connected with HVAC and HVDC systems, but most of the proposed controls focus only on onshore faults and lack in explaining the behavior of the system for offshore network faults, and particularly the response of VSC-HVDC system [7-12]. Generally, wind generators are recommended to injects the capacitive reactive current during fault to support the network voltage [13]. Also, this reactive current must be removed as fast as possible in post fault state, and the rate of active power recovery should also be high to ensure system stability during the recovery period [14]. In the offshore AC network formed by VSCs only, the analysis of network behavior with respect to current magnitude is not sufficient since the low fault voltage also introduces the voltage phase angle jump phenomena. The converters control rely on the voltage phase angle and any sudden jump in the angle could lead system into the instability [15]. 


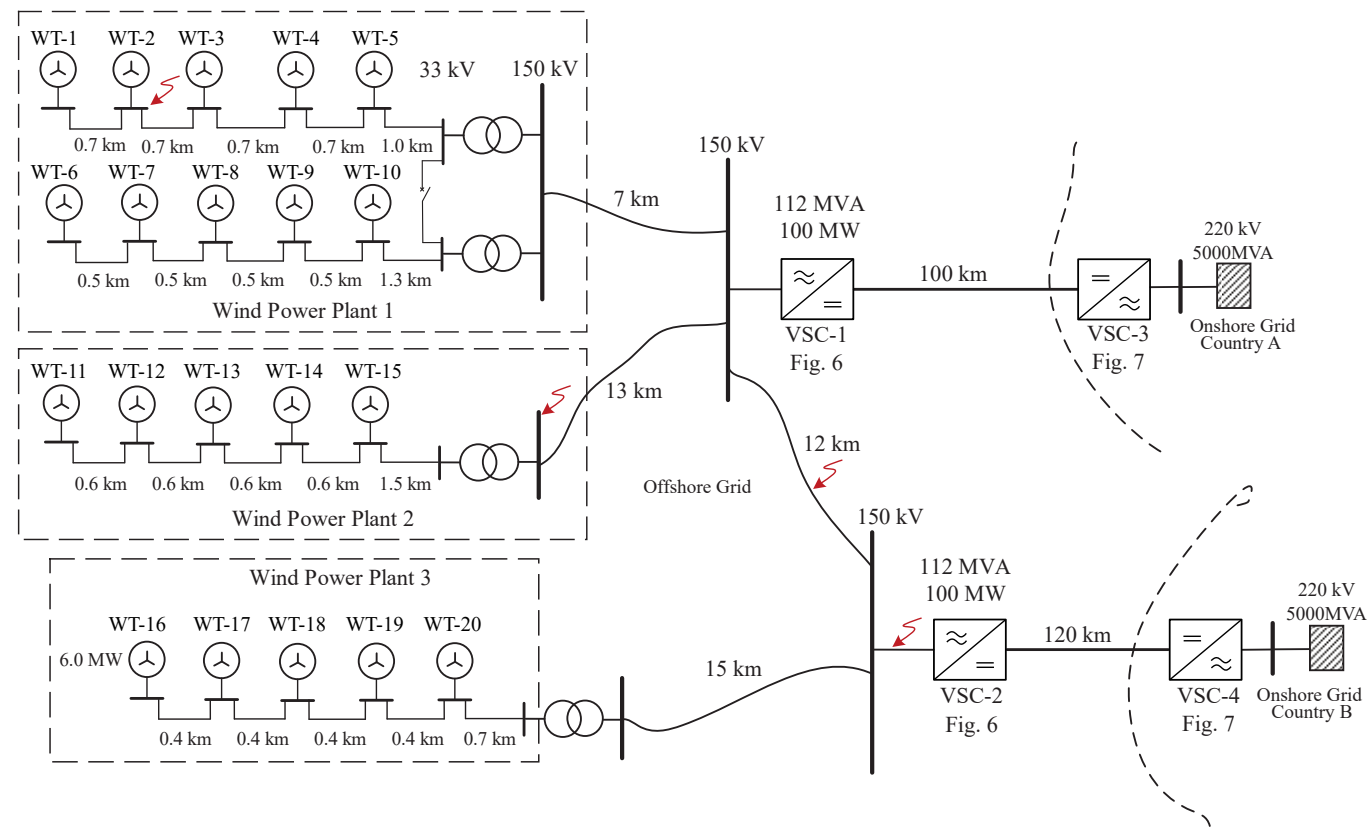

Figure 1: Offshore AC network configuration for short circuit analysis.

There are few studies that address this issue however they are limited to doubly-fed induction generator based wind turbine system [16, 17].

The parallel operation of the VSC in the offshore AC network provides the redundancy of reference machine in the network and enables the power distribution among several onshore grids [18]. The net power in the offshore network can be higher than a single VSC-HVDC system when connected with multiple VSC-HVDC system to interconnect several onshore grids [19]. On the other hand, the combined power of all the wind power plants is limited up to the converter capacity in case of single VSC-HVDC connection. The voltage and frequency droop schemes enables the power sharing among the parallel connected VSCs which provides an additional degree of freedom in reactive power management [19]. With the frequency droop scheme, powerfrequency relationship can be established in the VSC grid-forming control which can contribute in primary frequency regulation. In [20], frequency coordination scheme is proposed for parallel connecting VSC, however it does not address the fault condition in offshore AC network. Further, it is important to considered the stability limitation in the frequency droop value selection. The high droop value may produce fast frequency response in order 
to follow the need of wind power reduction however the fast transient lead system into instability [21]. Thus, there is a need to established an effective coordinated active power reduction scheme for wind turbine and VSC-HVDC transmission system.

In the presented article, the control system of wind generation and VSCHVDC system is developed considering effects of voltage phase angle jump during faults and the limitation of frequency transient. To address the problem, an offshore AC network is formed which is controlled by two VSC based HVDC transmission system and interconnecting three wind power plants. First, the converter control overview is given according to its operation in the network. Then, a method of calculating operational limits considering the PQ capabilities of the converter is proposed. Later, a short circuit analysis for an offshore AC fault is presented on the simplified network. In the end, a short circuit control and frequency coordinated scheme is presented and validated through nonlinear simulation.

\section{Offshore AC Network Interconnecting Different Wind Power Plants}

The structure of the offshore AC network is similar to the medium voltage distribution network at onshore. Traditionally, the short circuit current contribution of the converters in the distribution network is determined by defining the voltage source behind an impedance. This virtual impedance is calculated using converter rated current value. This is an inadequate modeling approach for the network in which converter current contribution is large such as in offshore network, and detail converter control loop dynamics are necessary to incorporate for short circuit analysis. In order to simulate and illustrate the proposed short circuit control scheme, an offshore AC network interconnecting three wind power plants with two onshore grids using VSC-HVDC transmission system is developed. This network configuration is shown in Fig. 1. The presented study focus only on offshore AC faults.

The network parameters are given in Table. 1. The wind power plants array consists of $33 \mathrm{kV}$ AC cable [22]. The interconnection of wind power plants with each other are done using cable $150 \mathrm{kV}$ AC cable [23]. Furthermore, the transformers parameters are derived using characteristics curves given in [24]. The short circuit control schemes are proposed for wind generation systems and offshore VSCs of HVDC transmission systems. The dynamics of onshore grids are not under consideration and it is assumed 
Table 1: Network parameters

\begin{tabular}{|c|c|c|}
\hline Variables & Value & Unit \\
\hline Medium Voltage AC Cable (MV) & 33 & $\mathrm{kV}$ \\
\hline MV Cable Resistance & 0.047 & $\Omega / \mathrm{km}$ \\
\hline MV Cable Inductance & 0.34 & $\mathrm{mH} / \mathrm{km}$ \\
\hline MV Cable Capacitance & 0.3 & $\mu \mathrm{F} / \mathrm{km}$ \\
\hline High Voltage AC Cable (HV) & 150 & $\mathrm{kV}$ \\
\hline HV Cable Resistance & 0.06 & $\Omega / \mathrm{km}$ \\
\hline HV Cable Inductance & 0.44 & $\mathrm{mH} / \mathrm{km}$ \\
\hline HV Cable Capacitance & 0.14 & $\mu \mathrm{F} / \mathrm{km}$ \\
\hline Transformer Voltage & $150 / 33$ & $\mathrm{kV}$ \\
\hline Transformer Resistance ${ }^{\mathrm{a}}$ & 0.79 & $\Omega$ \\
\hline Transformer Inductance ${ }^{\mathrm{a}}$ & 42.13 & $\mathrm{mH}$ \\
\hline DC Cable (Symmetrical monopole) & 150 & $\mathrm{kV}$ \\
\hline DC Cable Resistance & 0.019 & $\Omega / \mathrm{km}$ \\
\hline DC Cable Inductance & 0.1 & $\mu \mathrm{H} / \mathrm{km}$ \\
\hline
\end{tabular}

${ }^{\text {a }}$ refer to high voltage level.

that the onshore converters maintains the DC voltage within the operational limits. Four faults are considered in the offshore AC network for control system analysis i.e at MVAC busbar, HVAC busbar, HVAC cable and the disconnection of VSC-2 converter.

The offshore wind power plants $\mathrm{AC}$ cable length up to $20 \mathrm{~km}$ to form offshore AC hub is economically beneficial [18]. The cables length in the study network is set considering this factor and they are modeled as $\pi$-sections. Furthermore, the converters are represented by its average model. The use of voltage source converter has a large impact on the power system and an appropriate model is required for the system analysis. The detailed MMCVSC model contains large number of switching devices which slow down the simulation process due to small simulation time steps [25]. The use of detailed models is restricted to component level studies [26]. An averaged model which can reproduce the dynamic performance accurately is sufficient for the study of slow dynamic stability phenomena and performance analysis within a large scale AC network [26]. In the converter average model, the $\mathrm{AC}$ side is represented by three controlled voltage sources considering only the fundamental frequency, and the DC side is represented by a controlled current source. The converter average model diagram is shown in Fig. 2. 


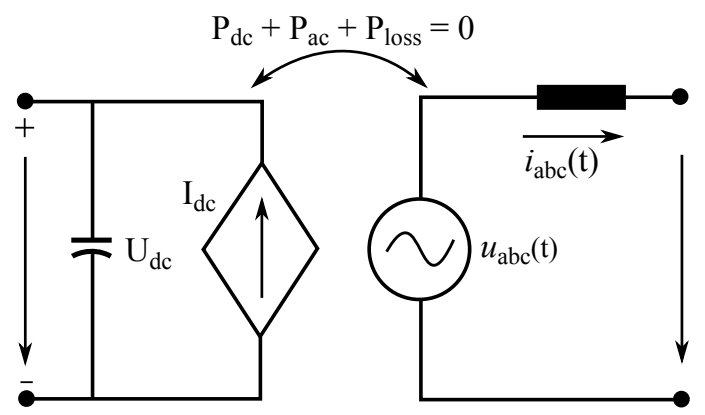

Figure 2: Voltage source converter average model.

The detail of the converter control is given in the following sections. The nonlinear simulation has been performed using Simulink Simscape Power Systems block-sets.

\subsection{Control of Wind Generation System}

Each wind turbines is equipped with a permanent magnet synchronous generator connected to the full power converter. In this case, the inertia of the wind turbine is isolated due to the DC link in converters, ergo, the response of the wind turbine is dominated by the offshore network side converter. The control system of wind generation is given in Fig. 3. The converter of the wind generation system is synchronized with the offshore AC network frequency and controls the current or power flow. In the wind generation unit configuration, converter is connected through the series reactor and transformer with the offshore AC network. It is considered that the harmonic content of the converter is low and it does not require additional filters. Further, offshore AC cables have high capacitance and the converter have sufficient capability to fulfill the network reactive power demand thus the filter capacitor is not installed in the wind generation units. On the DC side of the converter, the wind power in-feed is modeled as controlled DC current source connected in parallel to the DC filter.

The converter control system generates the balanced three phase reference signal $\left(u_{v s c \_a b c}\right)$. This reference signal is generated by transforming the converter output voltage control signal $\left(u_{v s c_{-} d q}\right)$ from $d q 0$ to abc frame by 


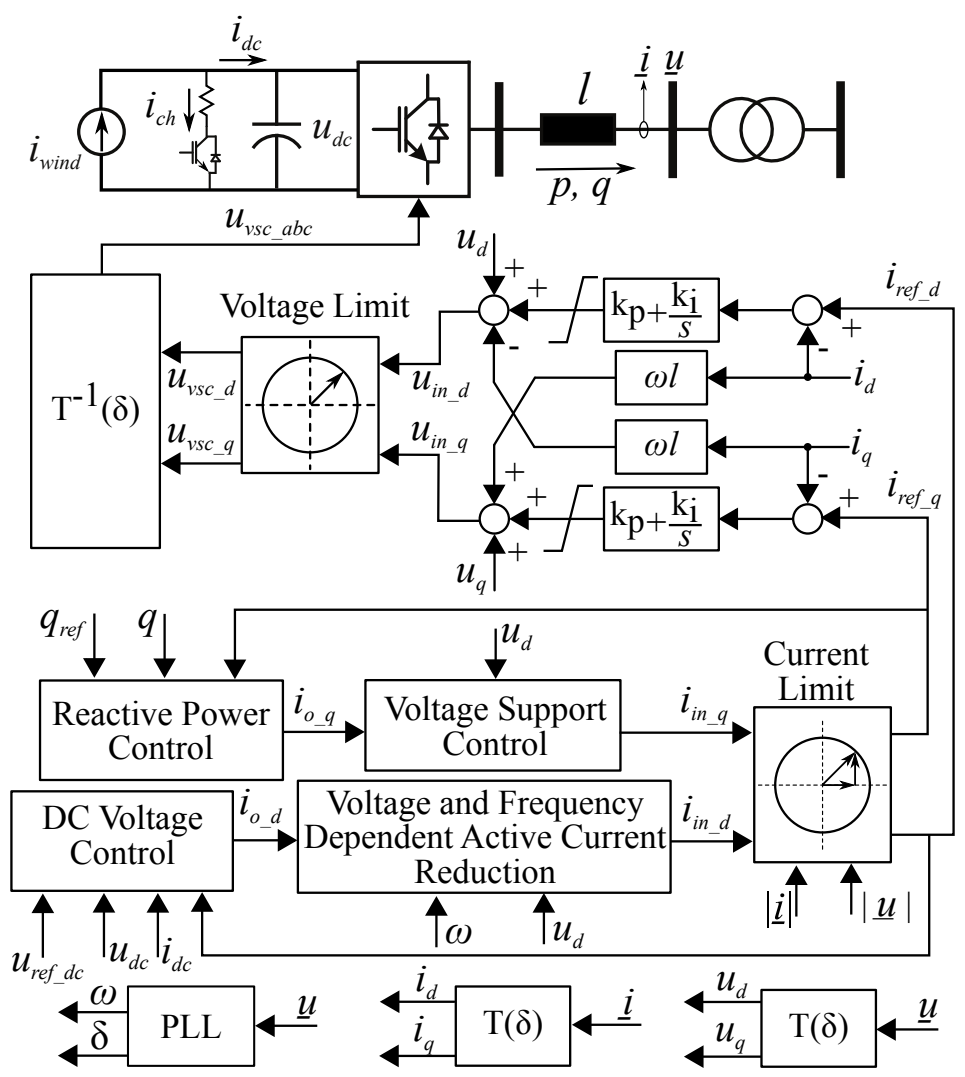

Figure 3: Control system of wind generation with fully rated converter

applying Clark transformation. The transformation matrix is given in (1).

$$
\begin{gathered}
T(\delta(t)) \cdot T^{-1}(\delta(t))=I(3 \times 3) \\
T^{-1}(\delta(t))=\left[\begin{array}{ccc}
\sin (\omega t) & \cos (\omega t) & 0.5 \\
\sin (\omega t-2 \pi / 3) & \cos (\omega t-2 \pi / 3) & 0.5 \\
\sin (\omega t+2 \pi / 3) & \cos (\omega t+2 \pi / 3) & 0.5
\end{array}\right]
\end{gathered}
$$

Converter control system includes current decoupling scheme and two main control closed loops i.e inner and outer control loop. The inner control is a current closed loop which controls the current flow through the series reactor. The time response of the current closed loop is adjusted to $2.0 \mathrm{~ms}$. The wind generation unit control parameters are given in Table. 2. The detail of inner and outer controller parameters selection method is given in [27]. The current $d$ - and $q$-component reference command is generated by 
Table 2: Wind generation unit control parameters

\begin{tabular}{lcc}
\hline Variables & Value & Unit \\
\hline Rated Power & 6.3 & $\mathrm{MVA}$ \\
Rated AC Voltage & 900 & $\mathrm{~V}$ \\
Rated DC Voltage & 2.0 & $\mathrm{kV}$ \\
Transformer Voltage & $33 / 0.9$ & $\mathrm{kV}$ \\
Transformer Resistance $^{\mathrm{a}}$ & 1.3828 & $\Omega$ \\
Transformer Inductance $^{\mathrm{a}}$ & 32.8 & $\mathrm{mH}$ \\
DC Filter Capacitance & 200 & $\mu \mathrm{F}$ \\
Reactor Resistance & 0.1 & $\mathrm{~m} \Omega$ \\
Reactor Inductance & 0.02 & $\mathrm{mH}$ \\
Current PI Controller gains & $0.156+0.778 / \mathrm{s}$ & $\mathrm{p} . \mathrm{u}$ \\
DC Voltage PI Controller gains & $0.0032+0.0635 / \mathrm{s}$ & $\mathrm{p} . \mathrm{u}$ \\
Reactive Power PI Controller gains & $0.5+10 / \mathrm{s}$ & $\mathrm{p} . \mathrm{u}$ \\
Network Frequency & 314.16 & $\mathrm{rad} / \mathrm{s}$ \\
\hline
\end{tabular}

${ }^{a}$ refer to high voltage level.

the outer control loop. The outer control loop perform two main operation. Firstly, DC voltage control to injects the generated wind power into offshore AC network. The DC voltage control of the wind generation unit is shown in Fig. 4. The DC voltage control consists of a PI regulator with anti-windup limits. The reference current $d$-component is applied as the feedback signal of the anti-windup limits in order to consider the current limiter output. The anti-windup scheme insure that the input of the integral remains near to the reference current signal during fault period. Secondly, converter controls the reactive power flow to support the offshore network voltage. The reactive power control of the wind generation unit is shown in Fig. 5.

Like in the DC voltage control, the feedback signal for the anti-windup in the integral of reactive power PI regulator is a reference current $q$ - component. Further, the integral output limits are calculated using PQ analysis given in later section. The remaining control blocks i.e voltage and current limits, voltage support control, voltage and frequency dependent active current reduction schemes play their role during short circuit and voltage recovery period which is explain in later sections. 


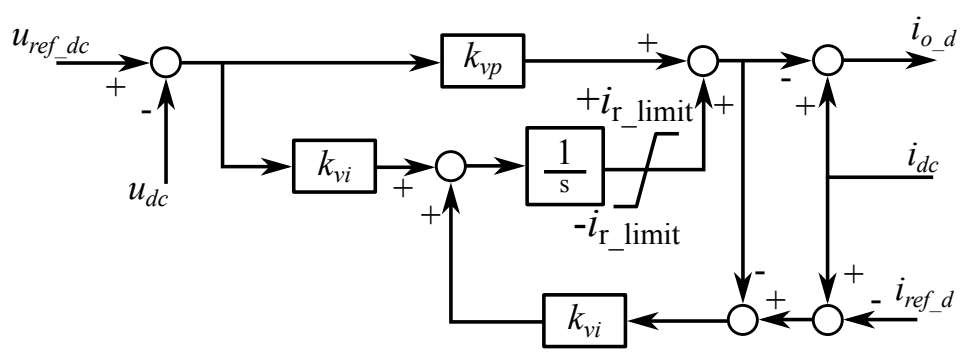

Figure 4: Wind generation DC voltage control system

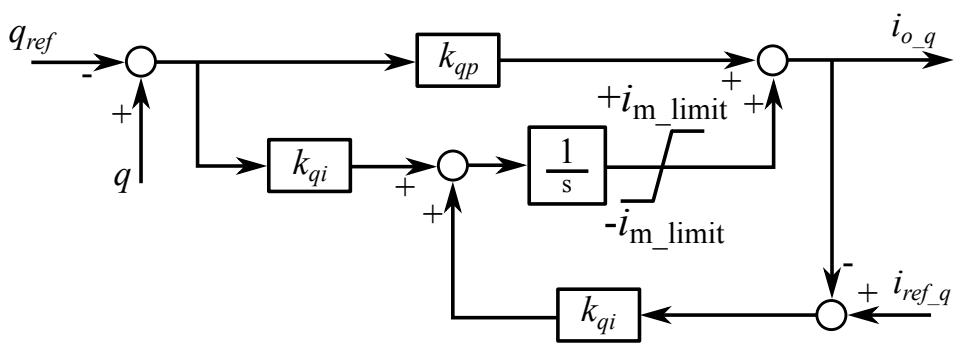

Figure 5: Wind generation reactive power control system

\subsection{Control of VSC-HVDC System}

The wind power from the offshore AC network is transferred to two onshore grids using VSC based HVDC transmission system in the point-to-point configuration. In such configuration, a transmission system has two converter stations located at onshore and offshore. The offshore VSC are operated in grid-forming mode in which it impose the frequency on the offshore $\mathrm{AC}$ network and energized it. In the presented study, both converters VSC1 and VSC-2 are controlling offshore network frequency and voltage using droop scheme. Both converters behave as reference machine in the offshore network and balance the power. The control of VSC-HVDC offshore side converter is shown in Fig. 6. The substation consists of a VSC and its control unit, series reactor, shunt AC filter, coupling transformer, and the DC filter. In the average model of the VSC, the voltage at the busbar connecting with the VSC can be considered as applied converter controlled voltage. The series reactor is designated as the arm inductance and/or additional inductance for smoothing current. Further, it also limits the short circuit current as well as enables the power flow control. The VSC control unit has current and voltage control loop in order to regulate the voltage at the filter busbar. The AC shunt filter is added in order to regulate the voltage at 


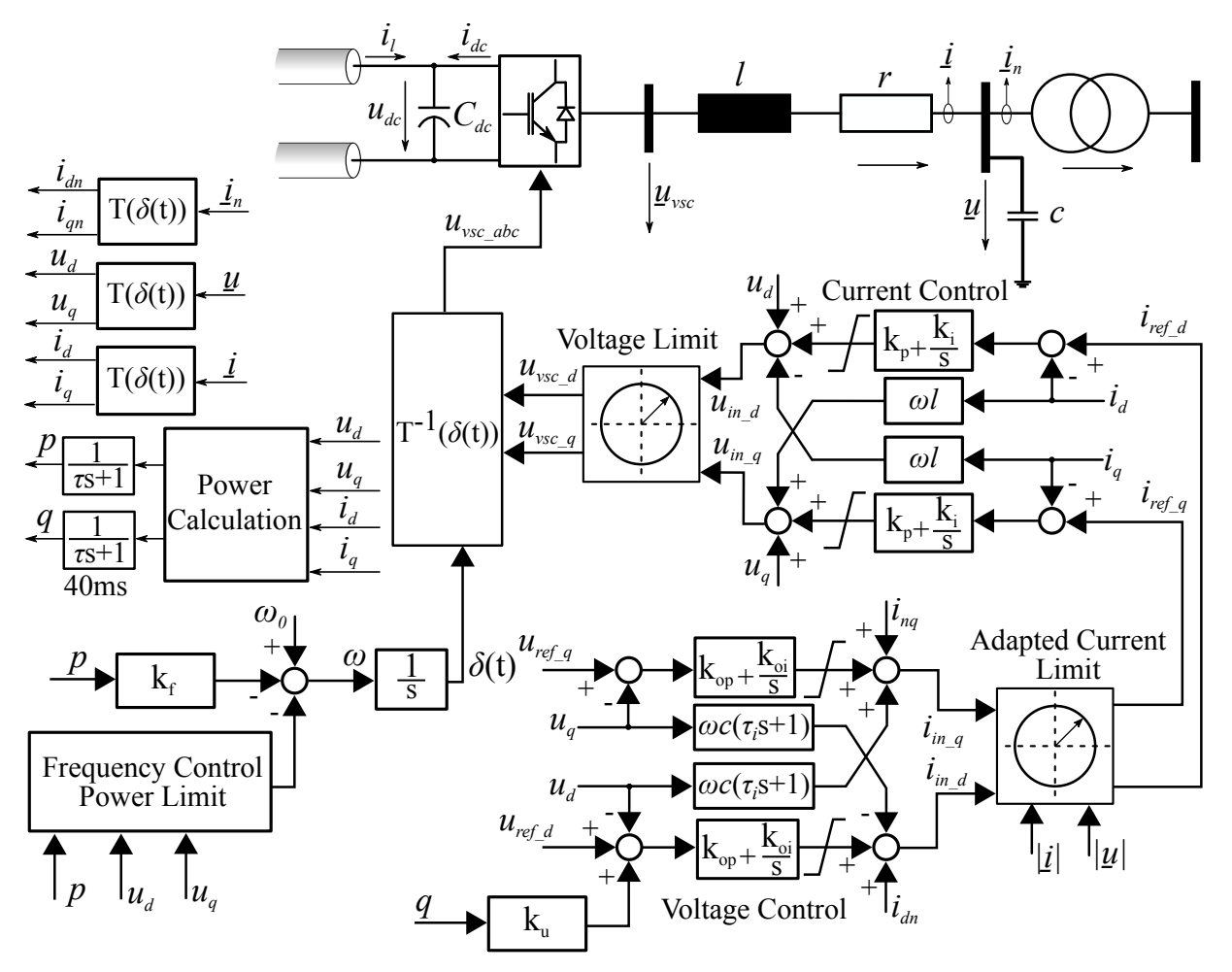

Figure 6: Control system of transmission system offshore converters

the non-floating busbar as well as it ensure the voltage stability and reduce high frequency transient in the voltage. The dynamic of the DC capacitors connected in the converter can be characterized by referring them with equivalent capacitance at DC side connecting in parallel with the current source. The transformer steps up the voltages and connects the VSC system with the network of different voltage levels. The offshore VSC substation parameters are given in Table. 3. The presented VSC grid-forming control scheme differ from the direct voltage control scheme presented in [1] in a way that it has current closed loop which enables the direct current control during short circuit. Furthermore, current control also improves the dynamic response in normal operation.

The frequency control of synchronous machine is different than the control of grid-forming VSC such that the frequency is controlled by balancing the mechanical power with electrical power. On the other hand, the grid-forming VSC controls the frequency directly like a frequency oscillator. A frequency 
Table 3: Offshore VSC substation and control parameters

\begin{tabular}{lcc}
\hline Variables & Value & Unit \\
\hline Rated Power & 112 & $\mathrm{MVA}$ \\
Rated AC Voltage & 110 & $\mathrm{kV}$ \\
Rated DC Voltage & \pm 150 & $\mathrm{kV}$ \\
Transformer Voltage & $150 / 110$ & $\mathrm{kV}$ \\
Transformer Resistance & 0.2410 & $\Omega$ \\
Transformer Inductance & 76.74 & $\mathrm{mH}$ \\
DC Filter Capacitance & 400 & $\mu \mathrm{F}$ \\
Reactor Resistance & 0.0363 & $\Omega$ \\
Reactor Inductance & 55 & $\mathrm{mH}$ \\
AC Filter Capacitance & 2.63 & $\mu \mathrm{F}$ \\
Current PI Controller gains & $0.51+0.34 / s$ & $\mathrm{p} . \mathrm{u}$ \\
Voltage PI Controller gains & $4.32+0.86 / s$ & $\mathrm{p} . \mathrm{u}$ \\
Network Frequency & 314.16 & $\mathrm{rad} / \mathrm{s}$ \\
Current Control Time Constant $\left(\tau_{i}\right)$ & 1.0 & $\mathrm{~ms}$ \\
Power Measurement Filter Time Constant $(\tau)$ & 40 & $\mathrm{~ms}$ \\
Frequency droop VSC-1 $\left(k_{f 1}\right)$ & 0.0002 & $\mathrm{p} . \mathrm{u}$ \\
Frequency droop VSC-2 $\left(k_{f 2}\right)$ & 0.0001 & $\mathrm{p} . \mathrm{u}$ \\
Voltage droop VSC 1 $\left(k_{u 1}\right)$ & 0.001 & $\mathrm{p} . \mathrm{u}$ \\
Voltage droop VSC 2 $\left(k_{u 2}\right)$ & -0.001 & $\mathrm{p} . \mathrm{u}$ \\
\hline
\end{tabular}

${ }^{a}$ refer to high voltage level.

droop scheme is applied in order to establish the link between the VSC power and the network frequency. In this way, multiple VSCs can be connected in parallel in the offshore $\mathrm{AC}$ network to operate system analogue to the synchronous machines principle. Additionally, the control over the active power distribution among the VSCs can also be achieved by adjusting the droop gains value. Similarly, the reactive power contribution of each VSCHVDC transmission system can also be controlled using voltage droop scheme [19]. Although the combined capacity of VSC-HVDC transmission systems must be equal to the total wind power, it is not necessary for each VSCHVDC transmission system to have equal or greater capacity than total wind power in the offshore AC network. However, the reduction in the wind power generation is required in the event of one transmission system disconnection up to the total remaining export capacity. This is achieved by applying frequency coordination scheme between wind generation units and in-service 


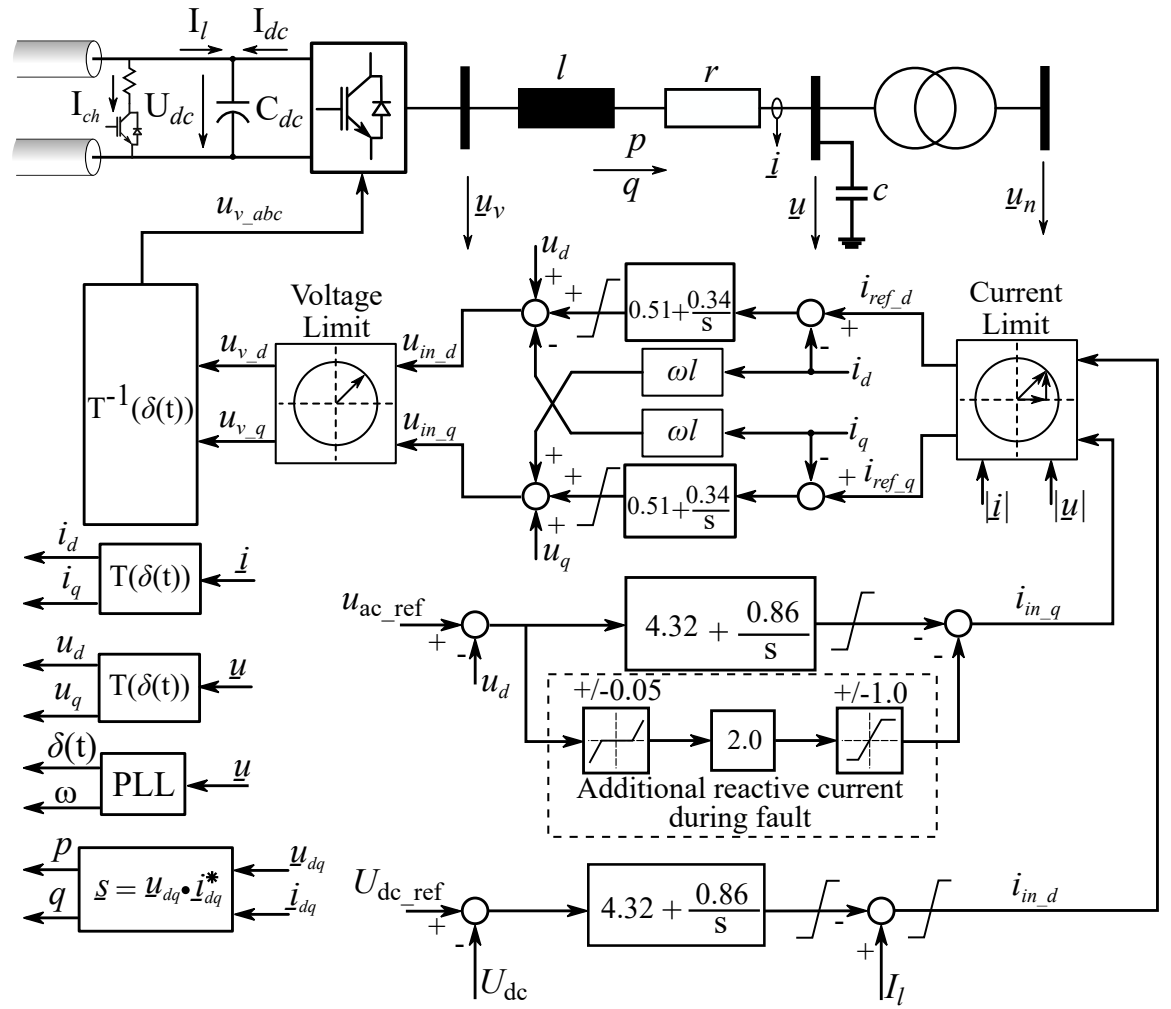

Figure 7: Control system of onshore converters of HVDC transmission system.

VSC-HVDC transmission system. Furthermore, the voltage and adaptive current limits controls the behavior of the VSC during short circuit. The frequency coordination and short circuit control principle is explained in later section.

The onshore converters of HVDC transmission system are operated in grid-synchronous mode. The onshore converters have the sole responsibility to control the DC voltage in order to balance the DC network. Also, the converters are set to control the $\mathrm{AC}$ voltage to support the onshore grid voltages. The onshore converter substation configuration is shown in Fig.7 and its parameters are given in Table. 4. The detail of onshore converter design is given in [27]. The rated power of offshore and onshore converters is same and the maximum current flow through offshore converters during disturbance is limited up to its maximum rating, thus the DC voltages are within the operational range and produce stiff response. In this regard, the transient of offshore $\mathrm{AC}$ network do not influence the onshore converters 
Table 4: Onshore VSC substation and control parameters

\begin{tabular}{lcc}
\hline Variables & Value & Unit \\
\hline Rated Power & 112 & $\mathrm{MVA}$ \\
Rated AC Voltage & 110 & $\mathrm{kV}$ \\
Rated DC Voltage & \pm 150 & $\mathrm{kV}$ \\
Transformer Voltage & $220 / 110$ & $\mathrm{kV}$ \\
Transformer Resistance $^{\mathrm{a}}$ & 0.52 & $\Omega$ \\
Transformer Inductance $^{\mathrm{a}}$ & 165.1 & $\mathrm{mH}$ \\
DC Filter Capacitance $_{\text {Reactor Resistance }}$ & 400 & $\mu \mathrm{F}$ \\
Reactor Inductance & 0.0363 & $\Omega$ \\
AC Filter Capacitance & 55 & $\mathrm{mH}$ \\
Current PI Controller gains & 2.63 & $\mu \mathrm{F}$ \\
Voltage PI Controller gains & $0.51+0.34 / \mathrm{s}$ & $\mathrm{p} \cdot \mathrm{u}$ \\
Network Frequency & 314.16 & $\mathrm{rad} / \mathrm{s}$ \\
Onshore Grid Short Circuit Power & 5000 & $\mathrm{MVA}$ \\
Onshore Grid Voltage & 220 & $\mathrm{kV}$ \\
\hline
\end{tabular}

${ }^{\mathrm{a}}$ refer to high voltage level.

control. Furthermore, the presented research only focus on the offshore AC network faults therefore further discussion on the onshore converters control is outside the scope of this article.

\subsection{Voltage and Current Operating Limits}

The calculation method applied to determine the converter voltage and current operational limits, is the same for both wind power plant and VSCHVDC system. These limits are selected with respect to the PQ characteristic of the system. An equivalent diagram of converter substation for the $\mathrm{PQ}$ analysis is shown in Fig. 8 and the parameters are given in Table. 4. Three connection points are important in the PQ analysis to determine the operational limits. Firstly, a PQ curve at the converter busbar that indicates the capability of the converter switching devices in term of current and voltage. Secondly, a PQ curve after the series reactor where the actual current limit requires to be applied in the control system. Thirdly, a PQ curve at the point of common coupling (PCC) which defines the normal operating region of the network.

Since, the ability of a converter to generate the AC output voltage peak 


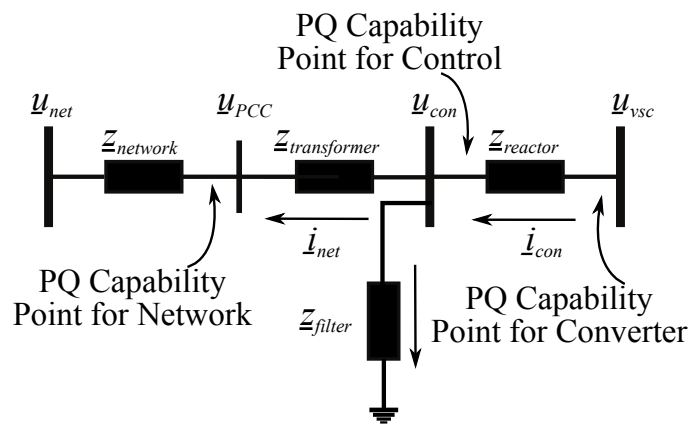

Figure 8: Converter substation equivalent diagram to analyze PQ characteristic

depends on the DC voltage level, the minimum and maximum DC voltage needs to be considered in the analysis. Typically, the onshore side converter controls the DC voltage in a point-to-point configuration of VSC-HVDC transmission system. The maximum and minimum DC voltage can be determined by calculating the voltage drop over the DC cable at maximum power using (2).

$$
\Delta U_{d c \_d e v}=\frac{R_{d c} \cdot P_{d c \_ \text {max }}}{U_{d c \_r t}^{2}}
$$

Where, $\Delta U_{d c \_d e v}$ is the per unit voltage deviation from the rated DC voltage, $R_{d c}(\Omega)$ is the total resistance of the DC cable, $P_{d c \_ \text {max }}(\mathrm{MW})$ is the maximum active power, and $U_{d c_{-} r t}(\mathrm{kV})$ is the rated pole-to-pole DC voltage.

The PQ analysis results are shown in Fig. 9. The unit circle is the rated power limit of the converter $\left(S_{v s c}\right)$ and the power flow is considered positive in the direction of arrows, as shown in Fig. 8. Reactive power upper and lower limits are imposed according to the converter $\left(u_{v s c}\right)$ maximum and minimum $\mathrm{AC}$ output voltage. It can be seen that the active power capability is not influenced significantly with respect to the DC voltage but reactive power capability varies. At the given active power limits, the inductive reactive power $\left(-Q_{\text {limit }}\right)$ is determined at minimum $\mathrm{AC}$ voltage and at maximum $\mathrm{DC}$ voltage, as illustrated in Fig. 9a. Care must be taken while selecting reactive power limits to not to violate all limits on PQ capability curve at both converter and control busbar. Moreover, the maximum capacitive reactive power limit $\left(Q_{\text {limit }}\right)$ is set by PQ curves at control busbar at maximum AC and at minimum DC voltage as illustrated in Fig. 9b. It can be noticed that capacitive reactive power limit is further reduced due to losses in the reactor. The operating region at the point of common coupling considering active 


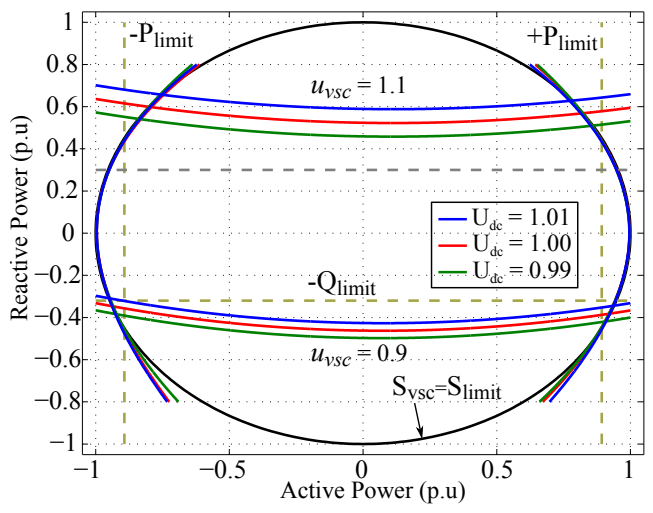

(a) PQ characteristic at VSC busbar

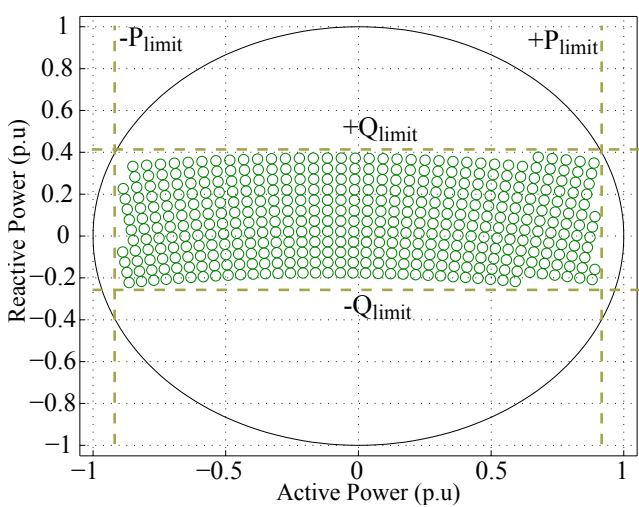

(c) PQ characteristic at PCC considering operating limits

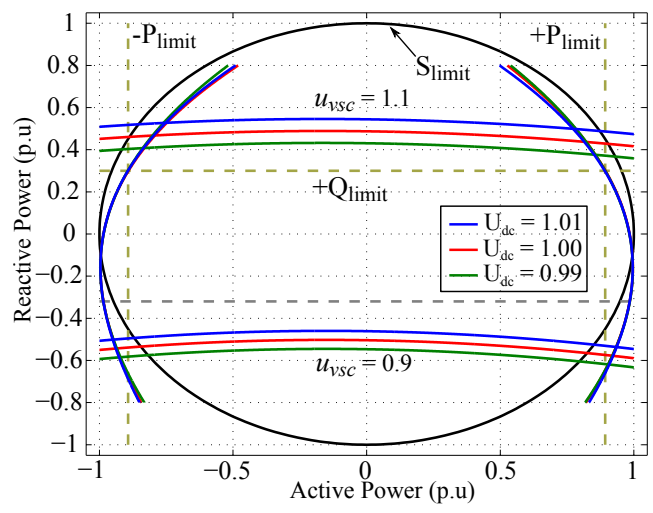

(b) PQ characteristic at control busbar

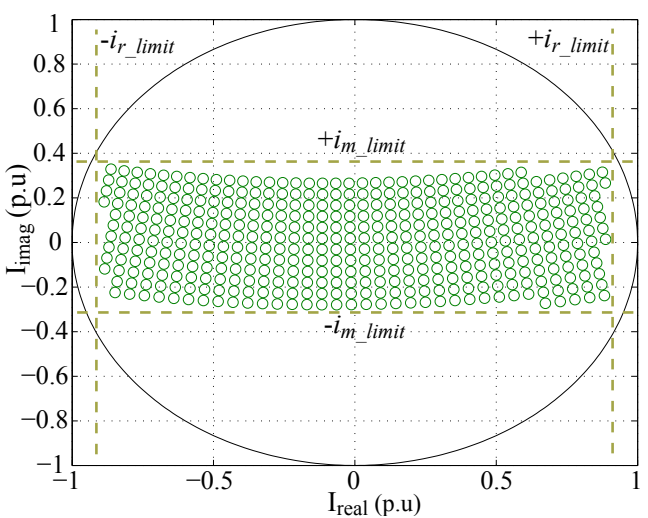

(d) $\underline{i}_{c o n}$ operational area considering PQ operating limits

Figure 9: PQ characteristic analysis of VSC-HVDC substation to determined voltage and current operational limits

and reactive power limits is shown in Fig 9c. Further, maximum steady state current limit for normal operation can be determined from Fig. 9d. The maximum required modulation index can be calculated using (3).

$$
m=\frac{u_{a c \_ \text {max }}}{U_{d c \_ \text {min }}} \cdot \frac{2 u_{p \_r t}}{U_{d c \_r t}}
$$

Where, $u_{\text {ac_max }}$ (p.u) is the maximum AC output voltage, $U_{d c \_m i n}(\mathrm{p} . u)$ is the minimum $\mathrm{DC}$ voltage for normal operation, $u_{p_{-r}}(\mathrm{kV})$ is the rated $\mathrm{AC}$ output voltage, and $U_{d c-r t}(\mathrm{kV})$ is the rated DC voltage. 


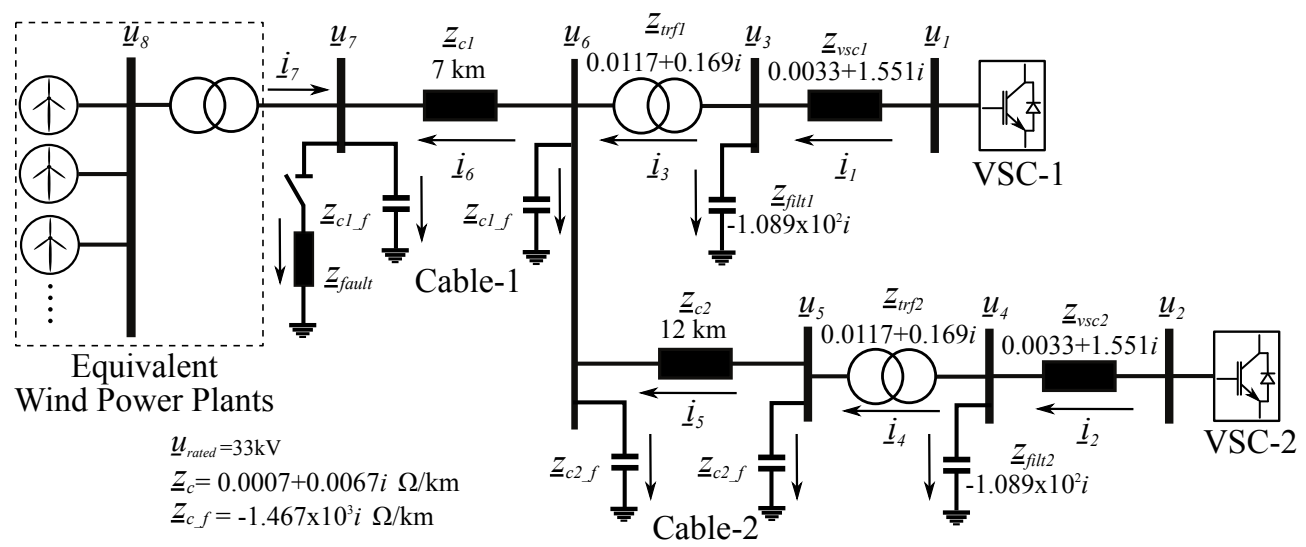

(a)

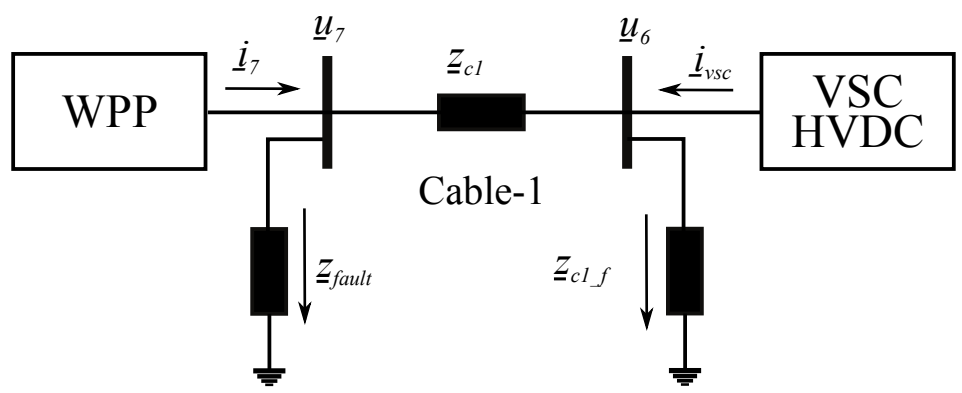

(b)

Figure 10: Simplified offshore AC network diagram for short circuit analysis.

\section{Short Circuit Analysis of an Offshore Grid}

The principle of VSCs short circuit control can be understood by performing circuit theory analysis on a simplified network given in Fig. 10. The length of cable 1 and 2 are $7 \mathrm{~km}$ and $12 \mathrm{~km}$ respectively. The wind power plants fault current contribution is represented by the net current $\left(\underline{i}_{7}\right)$ injected at the fault busbar $\left(\underline{u}_{7}\right)$. The VSCs behave as controlled voltage sources in the pre-fault state. However, these converters require to be operated as control current sources during fault which injects short circuit current up to the their maximum capability. In tradition approach of voltage source converter short circuit current analysis, it is considered that during short circuit period converter behaves as a voltage source behind the impedance and this virtual impedance is calculated using rated current value. Such assumption is not sufficient in the network where VSC has the sole responsibility to create/energized the network such as offshore grid and this model is inade- 
quate when current contribution is dominant and accuracy is important. The dynamics and nature of the current (inductive, capacitive, or pure resistive) play important role in the transient behavior of the voltage during fault and recovery period. During short circuit, the VSC current closed loop response is dominant therefore VSC-HVDC station is represented as current injected source in the equivalent circuit. This allows to analysis the voltage response according to the current.

The impact of the short circuit current on the network voltages during fault can be analyzed by defining the net current infeed $\left(\underline{i}_{v s c}\right)$ of the VSCs and the wind power plant current at the cable-1 ends as redrawn in Fig. 10b. Here, $\underline{z}_{\text {fault }}$ is the parallel combination of the fault impedance and the cable capacitive impedance $\left(\underline{z}_{c 1_{-} f}\right)$. In parallel combination, the fault impedance is dominant due to smaller in value therefore only the fault impedance is shown in the equivalent network diagram. The bus voltages as a function of VSC and wind power plant currents are derived as (4). Using this equation, the behavior of the bus voltages can be analyzed. It is clear that the voltages magnitude during fault are proportional to the magnitude of the currents. However, the contribution of the currents from wind turbines and VSCs in the busbars voltage level depends on the equivalent Thévenin impedance.

$$
\begin{aligned}
\underline{u}_{6} & =\frac{\underline{z}_{c 1_{-} f}}{\underline{z}_{c 1}+\underline{z}_{\text {fault }}+\underline{z}_{c 1_{-} f}}\left\{\left(\underline{z}_{c 1}+\underline{z}_{\text {fault }}\right) \cdot \underline{i}_{v s c}+\underline{z}_{\text {fault }} \cdot \underline{i}_{7}\right\} \\
\underline{u}_{7} & =\frac{\underline{z}_{\text {fault }}}{\underline{z}_{c 1}+\underline{z}_{\text {fault }}+\underline{z}_{c 1_{-} f}}\left\{\underline{z}_{c 1_{-} f} \cdot \underline{i}_{v s c}+\left(\underline{z}_{c 1}+\underline{z}_{c 1_{-} f}\right) \cdot \underline{i}_{7}\right\}
\end{aligned}
$$

According to the above equation, the voltage level of $\underline{u}_{6}$ will have high current contribution from $\underline{i}_{v s c}$ since the cable series impedance is higher than the fault impedance i.e $\left(\underline{z}_{c 1}+\underline{z}_{\text {fault }}\right)>\underline{z}_{\text {fault }}$. Similarly, the voltage level of $\underline{u}_{7}$ will be improved mainly by wind turbine current infeed. Apart of the current, the equivalent impedances also have high impact on the busbars voltage. The fault impedance introduces the voltage phase angle shift or phase angle jump due to difference in the equivalent impedance in fault and pre-fault states. The power electronic devices are sensitive to phase angle jump which lead to their mal-operation and cause instability in the network. During fault, the busbar voltage phase angle difference needs to be analyzed with respect to its pre-fault value as well as from other voltage sources bus voltage phase angle. In order to do so, the effect of the fault impedance on the voltage phase angle is analyzed by phasor diagram as shown in Fig. 11. The 


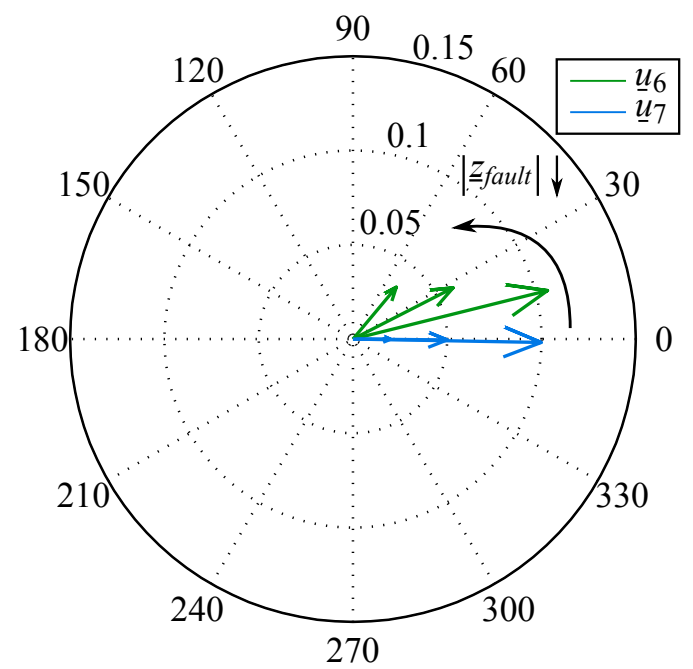

(a)

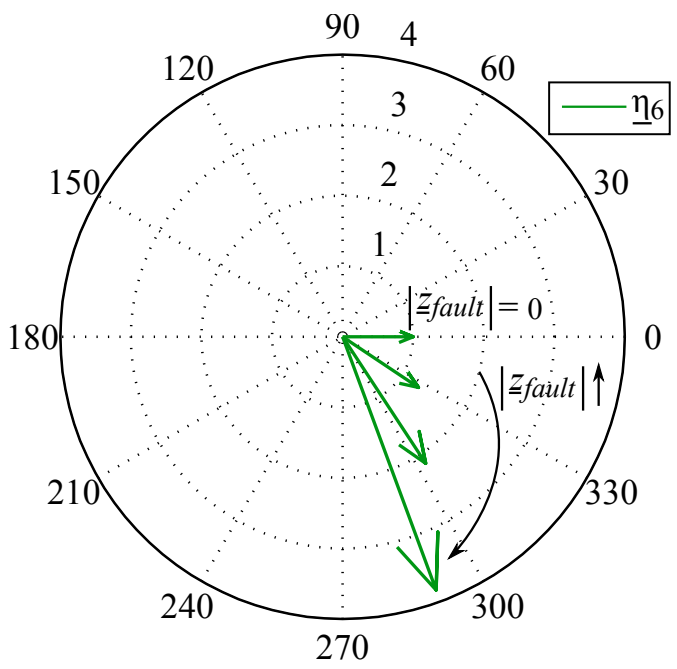

(b)

Figure 11: Effect of fault impedance magnitude on busbar voltages.

fault is considered as three phase resistive. In the results, the wind power plants are not injecting any current i.e $\underline{i}_{7}=0.0$ p.u, and the VSC injects rated current i.e $\underline{i}_{v s c}=1.0 \angle 0.0 \mathrm{deg}$. Here, this assume is applied in order to focus on the impact of VSC currents on the network voltages since the VSC-HVDC systems have the main responsibility to keep the voltage stable after fault clearance. Later, the wind turbine current infeed impact is also analyzed. Note that (4) represents the steady state voltage values during fault. Further, the converters are operating as controlled current sources during short circuit therefore its current can be taken as the reference vector on the complex plane. The voltage, current and impedance variables are expressed in polar coordinate to simply the notation as:

$$
\begin{aligned}
\underline{u}_{6} & =u_{6} e^{j \delta_{6}} \\
\underline{u}_{7} & =u_{7} e^{j \delta_{7}} \\
\underline{i}_{7} & =i_{7} e^{j \psi_{7}} \\
\underline{i}_{v s c} & =i_{v s c} e^{j \psi_{v s c}} \\
\underline{z}_{f a u l t} & =z_{f} e^{j \theta_{f}} \\
\underline{z}_{c 1} & =z_{c} e^{j \theta_{c}} \\
\underline{z}_{c 1_{-} f} & =z_{c f} e^{j \theta_{c f}}
\end{aligned}
$$


Typically, pre-fault voltage phase angle is near 0.0 deg from the reference bus considering no phase shifting transformer included. Fig. 11a illustrate that the phase angle of $\delta_{6}$ changes significantly with the reduction in the magnitude of the fault impedance, also the phase difference of both busbar $\left(\delta_{6}-\delta_{7}\right)$ increases proportionally. These large angle deviations can cause instability during fault and recovery period. Further, $\delta_{7}$ is not changed from its pre-fault value since the wind turbines current is zero, and its voltage appear due to converter current. Note that $z_{f}$ only influences $u_{7}$ but not $\delta_{7}$. To quantify the voltage angle deviation as function of equivalent impedance, a complex voltage ratio $\underline{\eta}_{6}$ is defined for busbar 6 as given by (6). Note that in the equation $\underline{i}_{7}=0.0$ p.u.

$$
\underline{\eta}_{6}=\frac{\underline{u}_{6}}{\underline{u}_{6}^{0}}=\frac{1+\frac{z_{f}}{z_{c}} e^{j\left(\theta_{f}-\theta_{c}\right)}}{1+\frac{z_{f}}{z_{x}} e^{j\left(\theta_{f}-\theta_{x}\right)}}
$$

Here, $\underline{z}_{x}=\underline{z}_{c 1}+\underline{z}_{c 1_{f} f}$. Also, $\underline{u}_{6}^{0}$ refers to the voltage at the busbar 6 when the fault impedance is zero. Fig. 11b illustrate the relative deviation in $\underline{\eta}_{6}$ with respect to voltage when the fault impedance is zero. On the complex plane, the reference vector is $\underline{u}_{6}^{0}$ i.e $1.0 \angle 0.0$ deg. The impedance of the cable capacitance is high relative to the fault impedance therefore denominator in (6) is constant i.e $1>z_{f} / z_{x}$. Thus, the voltage angle deviation mainly occurs due to the cable series impedance angle which is inductive i.e $\theta_{c} \approx 90 \mathrm{deg}$. With the increase in the $z_{f}$, the voltage at busbar 6 increases since the condition $1<z_{f} / z_{c}$ is applied. In the plot, $\theta_{f}$ is constant at the value of $0.0 \mathrm{deg}$. This has demonstrated that the phase angle jump is the function of the equivalent fault impedance which varies according to the fault location.

The system equations can be extended in the similar manner to analyze voltages behaviour of the whole network as shown in Fig. 11a. The offshore network voltages response for pre-fault and fault state is shown in Fig. 12. On the complex plane, the pre-fault voltage at the filter bus in the VSC substation is considered as reference phase angle i.e $\underline{u}_{3}=\underline{u}_{4}=1.0 \angle 0.0 \mathrm{deg}$. In the pre-fault state, the network voltage angles are close to reference busbar voltage angle as illustrated in Fig. 12a. It is well known that the voltage phase angle difference between busbars must be less than 90 deg to ensure stability in the network, and for practical reasons phase difference is preferable to be within the \pm 30 deg.

VSCs control the current injection during the fault period. Thus, the 


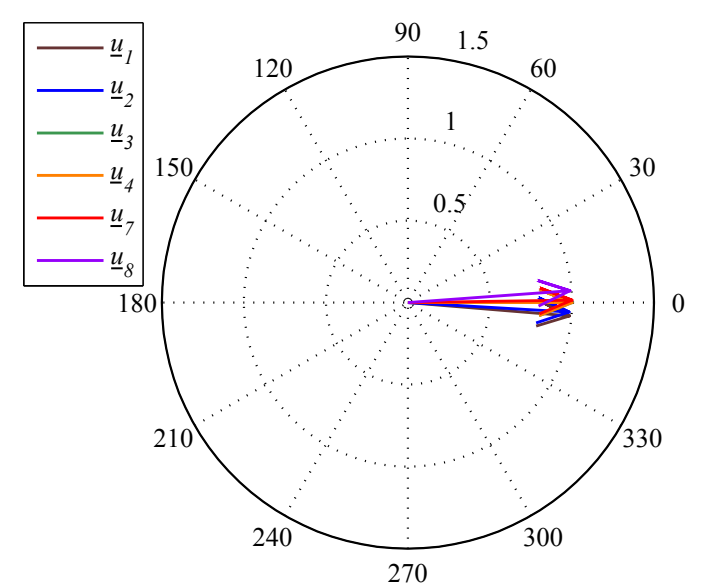

(a) Pre-fault network voltages

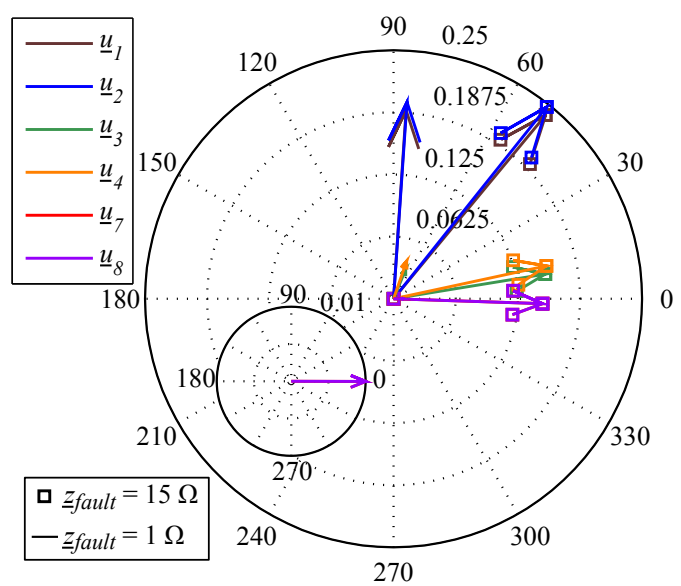

(b) Fault response with $\underline{i}_{1}=\underline{i}_{2}=1.0 \angle 0.0$, and $\underline{i}_{7}=0.0 \angle 0.0$

Figure 12: Offshore network voltages level in polar coordinates.

voltages in the network evolve according to the current in-feed and short circuit impedance of the network. The network voltages during fault with VSCs current in-feed of 1.0 $\angle 0.0$ deg each is illustrated in Fig. 12b. Note that wind power plants are not injecting any current in this case. The response has been analyzed for resistive faults at the value of $\underline{z}_{\text {fault }}=15 \Omega$ and $\underline{z}_{\text {fault }}=$ $1 \Omega$. It can be seen that the VSC substation busbar voltages have large voltage angle deviation with respect of its pre-fault state for low impedance fault. This is due to the dominance of cable reactance in the equivalent impedance during fault. Note that the angle of $\underline{u}_{7}$ is in phase with $\underline{u}_{8}$. When $\underline{z}_{\text {fault }}=1 \Omega$, the voltage magnitude at the fault bus is $0.01 \mathrm{p} . \mathrm{u}$, and $0.04 \mathrm{p} . \mathrm{u}$ at VSC controlling bus. At fault impedance of $\underline{z}_{\text {fault }}=15 \Omega$, the voltage phase angles will follow the difference of the cable series impedance and the equivalent fault impedance angle.

As explained earlier, that the large voltage angle deviation from its prefault state can cause large transient during recovery period and system can become unstable. Thus, the voltage angle of the VSC substation busbar can be rotated with the change in VSC current angle in order to reduce the deviation. In Fig. 13a, the response of the network voltages is shown for the case when VSCs inject current with the value of 1.0 $\angle-90 \mathrm{deg}$. It is clear that the voltage angle has improved for $\underline{z}_{\text {fault }}=1 \Omega$. On the other hand, voltage angles deviation increases for $\underline{z}_{\text {fault }}=15 \Omega$, since the voltage angle at the 


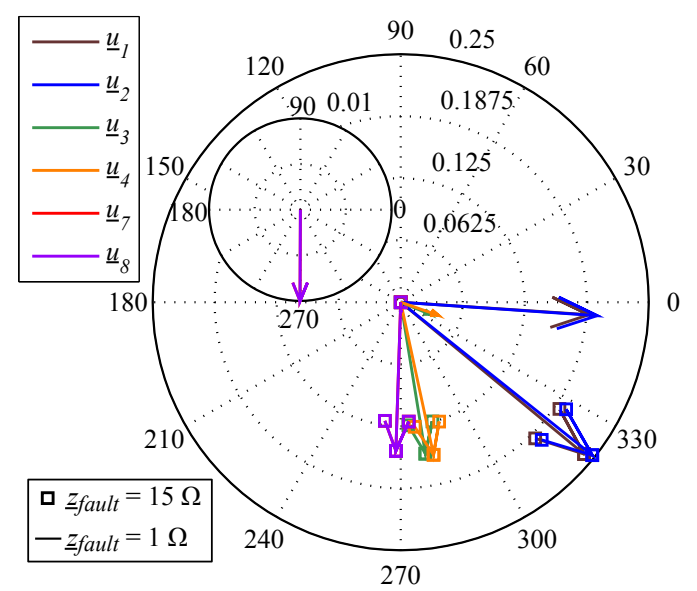

(a) Fault response with

$\underline{i}_{1}=\underline{i}_{2}=1.0 \angle-90$, and $\underline{i}_{7}=0.0 \angle 0.0$

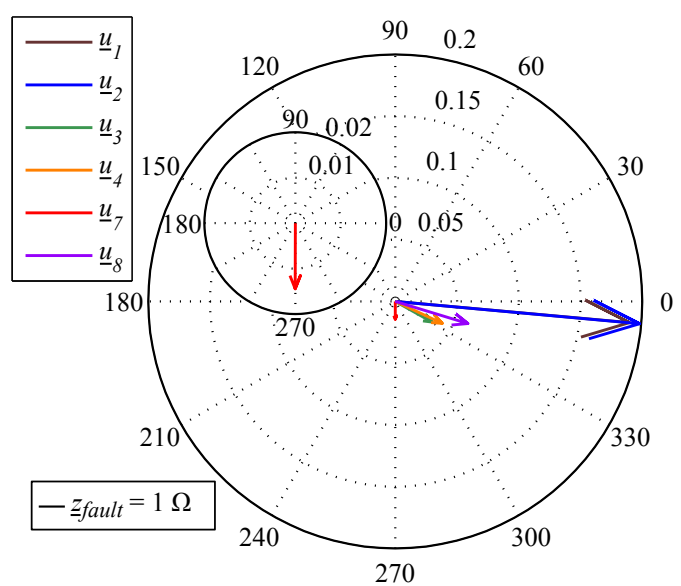

(b) Fault response with

$$
\begin{aligned}
\underline{i}_{1}=\underline{i}_{2} & =1.0 \angle-90.0, \text { and } \\
\underline{i}_{7} & =1.0 \angle-90.0
\end{aligned}
$$

Figure 13: Offshore network voltages with and without wind power plant current in-feed.

VSC busbar is the sum of the equivalent impedance angle and VSC current angle. It can be concluded that the VSC current is required to be controlled according the equivalent impedance as seen from its controlling busbar (filter bus) in order to keep its busbar voltage angle near to pre-fault state. Further, the magnitude of the VSC substation voltages are not effected by the current angle rather they are proportional to the magnitude of the current. Thus, the VSCs must inject current of maximum magnitude in order to maximize the voltages during fault.

As it has been observed that the voltages at the wind power plants busbar $\left(\underline{u}_{8}\right)$ mainly depends on the fault busbar voltages. The improvement in the voltage at the busbar 8 can be done by wind power plant current injections as shown in Fig. 13b. It is clear that the current injection with the angle -90 deg by the wind power plants improves both the magnitude and angle of $\underline{u}_{8}$. The fault bus voltage can be calculated using (7).

$$
\underline{u}_{7}=\underline{z}_{\text {fault }} \cdot\left(\underline{i}_{7}+\underline{i}_{6}\right) \quad \text { where } \underline{i}_{6} \approx \underline{i}_{1}+\underline{i}_{2}
$$

In the above analysis, the effect of fault impedance magnitude on the voltage phase angle has been observed. Further investigation of (6) indicate that the voltage phase angle jump may also be occurred due to change in the cable and fault impedance angles. To analyze the effect of cable length, 


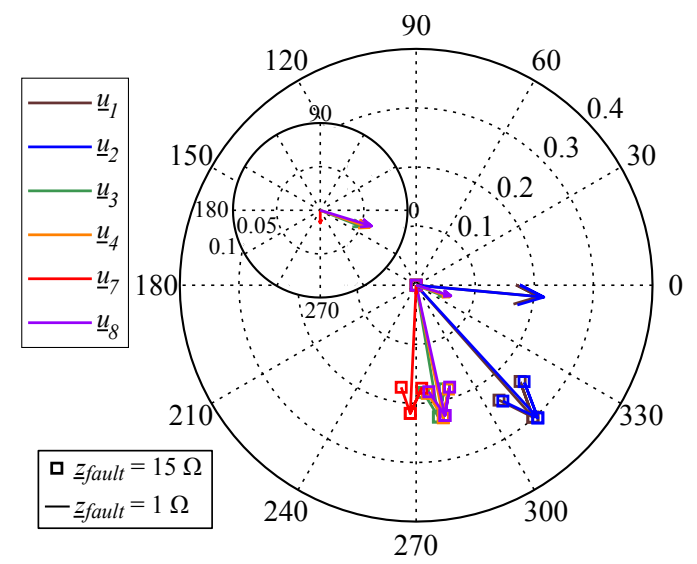

(a) Cable-1 length $=20 \mathrm{~km}$, $\underline{i}_{1}=\underline{i}_{2}=1.0 \angle-90$, and $\underline{i}_{7}=1.0 \angle-90.0$

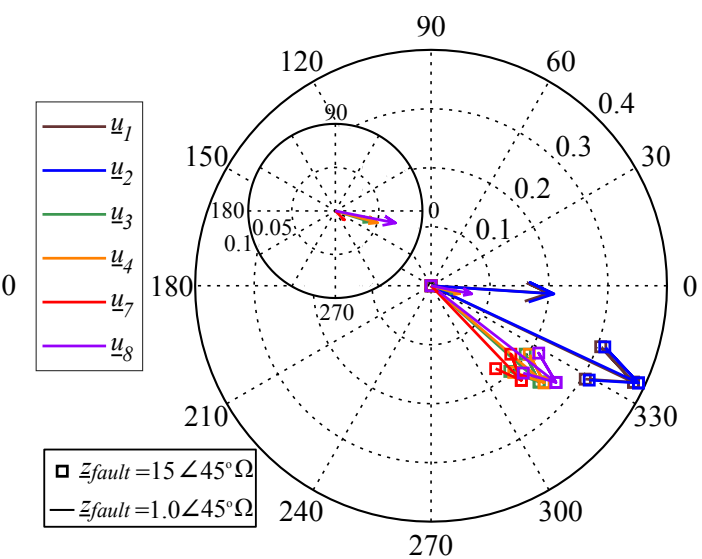

(b) $\underline{i}_{1}=\underline{i}_{2}=1.0 \angle-90.0$, and $\underline{i}_{7}=1.0 \angle-90.0$

Figure 14: Effects of cable length and fault impedance angle.

cable-1 length is changed to $20 \mathrm{~km}$ and the response of the voltages are shown in Fig. 14a. The voltage phase jump is not being influenced much compared to the response shown in Fig. $13 \mathrm{~b}$ due to same $X / R$ ratio of the cable. The length of the cables will not effect the phase of the voltage but it effects the magnitude. The reactive part of the offshore cable impedance is larger than resistive part and the effective $X / R$ ratio will mainly changes with the change of fault angle i.e $\delta_{f}$. The effect of $\delta_{f}$ on the voltage phase angle is shown in Fig. 14b. Here, the length of cable-1 is $7 \mathrm{~km}$ and fault is applied with $\delta_{f}=45 \mathrm{deg}$. It is clear that the pure resistive fault is the most sever case and less voltage phase jump occurs with the inductive fault impedance.

As discuss above, the voltage phase angle jump mainly appear due to series cable impedance which typically have impedance angle near to $90 \mathrm{deg}$. Therefore, the current infeed with angle greater than 0 deg would further increase the voltage phase angle jump and lead system into instability. The current infeed angle in the range of $0>\psi_{v s c}>-90 \mathrm{deg}$ improves the system response.

\section{Short Circuit and Frequency Coordinated Control System}

There are two main aspects of large signal disturbance that needs to be considered in the control system for an offshore AC network i.e the short 
Table 5: Short circuit control parameter of offshore VSC

\begin{tabular}{lcc}
\hline Variables & Value & Unit \\
\hline$u_{\text {max_limit }}$ & 1.09 & $\mathrm{p} . \mathrm{u}$ \\
$i_{\text {limit }}$ & 0.92 & $\mathrm{p} . \mathrm{u}$ \\
$k_{\text {lim }}$ & 10 & $\mathrm{p} . \mathrm{u}$ \\
$k_{s}$ & 15 & $\mathrm{p} . \mathrm{u}$ \\
$u_{\text {ref_d }}$ & 1.0 & $\mathrm{p} . \mathrm{u}$ \\
$k_{f s}$ & 0.006 & $\mathrm{p} . \mathrm{u}$ \\
\hline
\end{tabular}

circuit and the disconnection of one transmission system. The short circuit in the network leads to low voltages. In this case, converters behave as a controlled current source injecting maximum current. After fault isolation, the network must be restored as fast as possible and even create more than one isolated network if needed, such as in case of fault on interconnected cable $(12 \mathrm{~km})$ as shown in Fig. 1. In the case of disconnection of one transmission cable, the net energy exceeds the capacity of the in-service VSC-HVDC transmission system. Then, the network frequency needs to be increased by the in-service VSC-HVDC system to coordinate with the wind turbines in order to reduce their power generation up to the limit of export capacity. In this section, the control system of VSC-HVDC and wind generation units is discussed to cover these two aspects.

\subsection{VSC-HVDC Short Circuit Control}

The short circuit protection scheme is developed by controlling the converter output voltage and series reactor current. The voltage limit is applied using (8) at the output command signal of the VSC to limit the output peak voltage. For near VSC short circuit fault, the output voltage can drop to zero therefore the lower limit of output command signal is set to zero. The upper limit is set according to the PQ capability of the converter. The maximum output voltage rise is $1.1 \mathrm{p} . \mathrm{u}$ however this limit is reduced to $1.09 \mathrm{p} . \mathrm{u}$ by considering the voltage drop over the DC cable. The angle of VSC output voltage command is imposed according to the current flow through the VSC. Saturation limit is not applied on $\delta_{v s c}$ since the angle during fault depends on the equivalent impedance of the network as seen from the VSC busbar and short circuit current which varies according to fault. The voltage angle is 
controlled through current limits according to the analysis given in Section. 3 .

$$
\begin{aligned}
\left|u_{v s c}\right| & = \begin{cases}\left|u_{i n}\right| & \text { if }\left|u_{i n}\right|<\left|u_{\text {max_limit }}\right| \\
\left|u_{\text {max_limit }}\right| & \text { if }\left|u_{i n}\right| \geq\left|u_{\text {max_limit }}\right|\end{cases} \\
\delta_{v s c} & =\delta_{i n} \\
u_{i n} & =\sqrt{u_{i n_{-} d}^{2}+u_{i n \_q}^{2}}, \quad \delta_{i n}=\tan ^{-1}\left(\frac{u_{i n_{-} q}}{u_{\text {in_d }}}\right) \\
u_{v s c \_d} & =u_{v s c} \cos \left(\delta_{v s c}\right), \quad u_{v s c \_q}=u_{v s c} \sin \left(\delta_{v s c}\right)
\end{aligned}
$$

The current limits are imposed by controlling the reference current command and limits at PI regulator of current closed loop output. According to the current closed loop control model, the output of the PI regulator corresponds to the change in voltage drop across the series reactor which consequently control the current flow through it [27]. The maximum voltage drop across the series reactor can be calculated using (9) at the rated current value. The calculated voltage drop value can be set as the PI regulator output limits. In additional, anti-windup scheme ensure that the input of the integral do not exceed above the saturation limits and improves the transient behavior during recovery period.

$$
\Delta u_{\text {reactor }}=Z_{\text {reactor }} \cdot i_{p_{-} r t}
$$

The reference current command signal control scheme for short circuit is shown in Fig. 15. In normal operation, the reference signal $\left(i_{\text {in_d }}, i_{\text {in_q }}\right)$ is generated by outer voltage control loop as shown in Fig. 6. Saturation limit is applied on the magnitude of the reference current signal in which upper limit is regulated with PI controller by comparing the measured current flow $(|\underline{i}|)$ with the maximum current limit. The limit value of maximum absolute current magnitude is calculated according to the PQ characteristic of the converter i.e $i_{\text {limit }}=\sqrt{i_{r_{-} \text {limit }}^{2}+i_{m_{-} \text {limit }}^{2}}$ (see Fig. 9d). Once this limit exceeds, the upper limit PI regulator enforce the current magnitude to be equal or less than the $i_{\text {limit }}$. As analyzed in Section 3 that the current infeed angle of $-90 \mathrm{deg}$ is suitable to reduce the voltage phase angle jump. It is also concluded that the phase angle jump largely occurs due to series cable impedance angle. This would occur mainly when the fault is sever i.e the fault voltage drops near to $10 \%$. The current infeed angle during short circuit is controlled through low voltage fault scheme as shown in Fig. 15. 


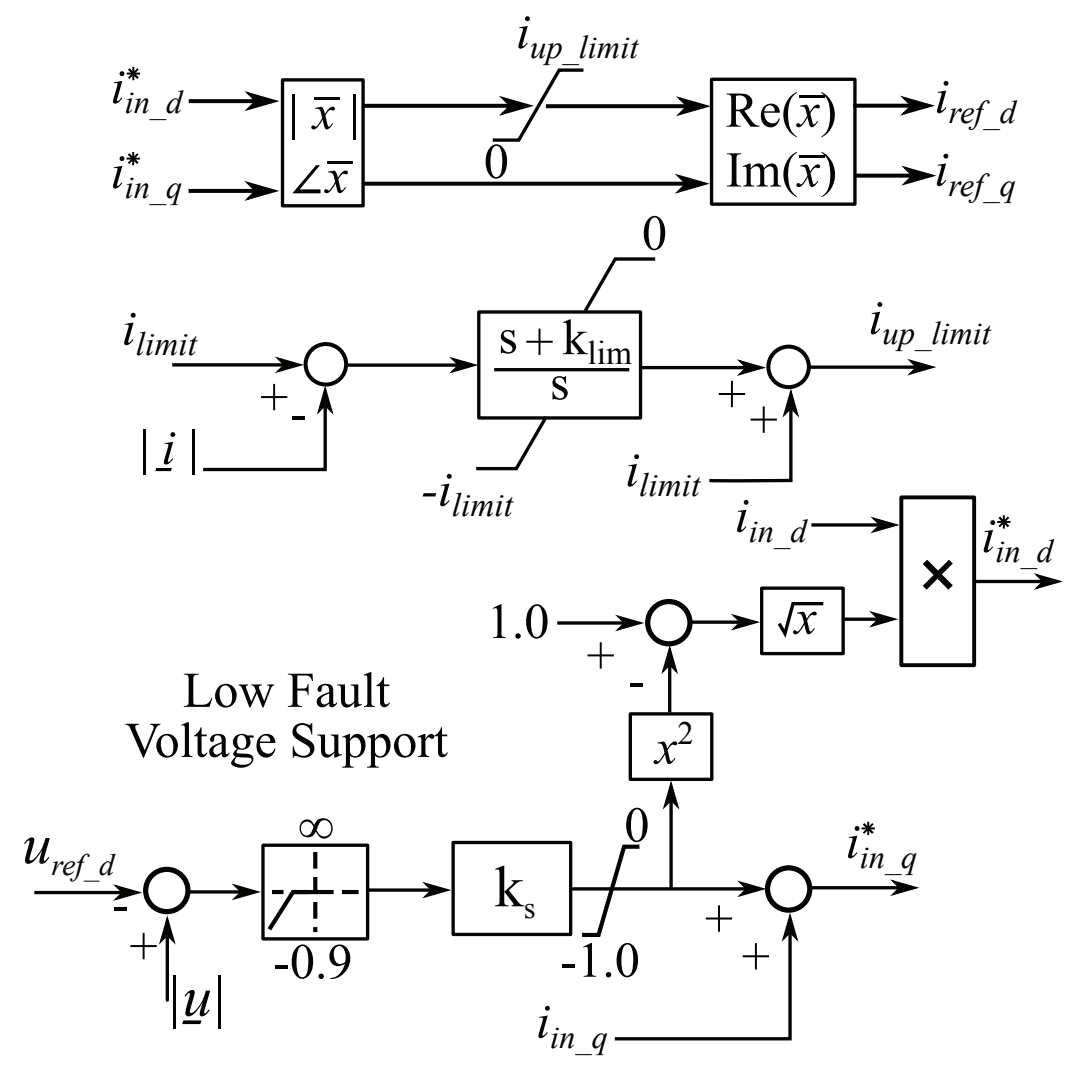

Figure 15: Adaptive current limit scheme for VSC-HVDC offshore converter

In low voltage fault scheme, the current reference command $d$-component is reduced as the fault voltage drop less than $10 \%$ and increases the current reference command $q$-component. According to $d q 0$ transformation rotation alignment used, $-i_{q}$ indicates the capacitive reactive current flow. Note that $d$-component would be positive during fault to fulfill the network current demand. The factor of current each components can be controlled by adjusting the value of $k_{s}$. The value of the $k_{s}$ can be adjusted between 10 to $25 \mathrm{p} . \mathrm{u}$ and it is calculated using (10).

$$
k_{s}=\frac{i_{v s c}}{u_{\text {fault }}}=\frac{1.0}{0.1}=10 \mathrm{p} . \mathrm{u}
$$

Here, $u_{\text {fault }}$ is the fault voltage at the VSC controlling busbar and $i_{v s c}$ is the reactive current to be infeeded by VSC at the fault voltage.

The reference current signal is generated by the outer voltage control. 


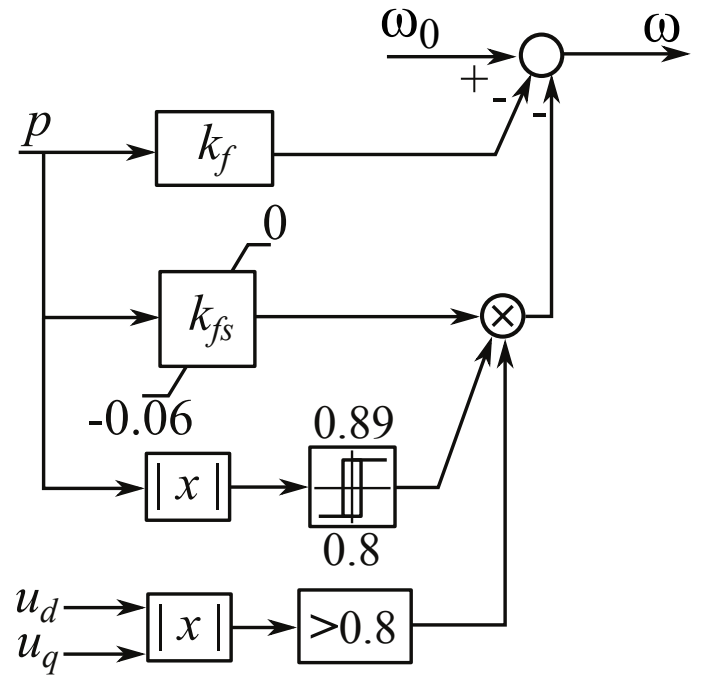

Figure 16: Frequency control power limit with droop control for VSC-HVDC system

The outer voltage control have the PI regulator and the feed-forward network current signal $\left(i_{n d}\right.$, and $\left.i_{n q}\right)$. At steady-state, the output of the voltage PI regulator is zero for successful reference signal tracking and the network current value will be equal to the amount of current flow through the VSC. The network current incorporation as the feed-forward signal to defined the VSC reference command enables the converter to follow the network current demand for fast transient response instead of relying solely on change in voltage across AC filter. With the proposed adaptive current control limits, the reference current command signal is not required to define explicitly and avoid the toggling of reference value, consequently improves the transient response during recovery period. In the proposed scheme, the reference current signal evolve according to the network current demand and switching between voltage and current operational mode happen gradually.

\subsection{VSC-HVDC Frequency Coordinated Control}

Typically, the low voltage level in the network is an indication of the short circuit. However, in case of a transmission system disconnection (open circuit fault), network AC voltage will rise due to excess energy in the network. In this case, VSC communicates through frequency with the wind generation system to indicate the need of reducing power generation up to the maximum export capacity. 
The VSC frequency control system in conjunction with droop control is shown in Fig. 16. The power-frequency droop gain has two components. The first component $\left(k_{f}\right)$ enables the power sharing among VSC-HVDC system. The gain $k_{f}$ is set such that the maximum change in network frequency does not exceed the threshold hold limit in the wind turbines i.e. $50.2 \mathrm{~Hz}$ [19]. The second gain component $\left(k_{f} s\right)$ is activated when the network voltage is higher than 0.8 p.u, and the actual active power through the converter exceeds active power operational limits. The gain $\left(k_{f s}\right)$ is set to increase the reference system frequency above the threshold limit of wind turbines. The rise in frequency triggers the active current reduction control in wind generation system, and the steady state in the system is achieved at the reduced wind power generation, limited up to the export transmission capacity. According to the design setting, the maximum frequency rise would be up to $1.06 \mathrm{p} . \mathrm{u}$. This maximum frequency rise limit is set according the TSO offshore grid code requirements given in [5]. Note that this is the maximum frequency rise by the VSC and at such frequency increase all the wind turbine should reduces $100 \%$ power generation. The actual change in frequency according to the in-service VSC-HVDC transmission system export capability can be calculated using (13).

\subsection{Wind Generation Short Circuit Control}

The wind generation converter output voltage limit is applied in a similar manner using (8). The integral output of the current controller is also limited by calculating maximum voltage drop across series reactor at rated current value using (9), this improves the integral input to avoid overshoot in error signal during fast transient through anti-windup scheme using back substitution. The wind generation converter system is operated in a grid synchronous mode and its behaviour in the network is as a controlled current source. Therefore, priority based current limit is applied as expressed by (11) and (12). The priority is given to the reactive current if the network voltage drop below 0.8 p.u otherwise active current has priority.

$$
\begin{aligned}
& i_{\text {ref_d }}= \begin{cases}\chi \cdot i_{i n_{-} d}^{*} & \text { if }|\underline{u}|<0.8 \wedge|\underline{i}| \geq 1.0 \\
i_{\text {in_d }} & \text { otherwise }\end{cases}
\end{aligned}
$$

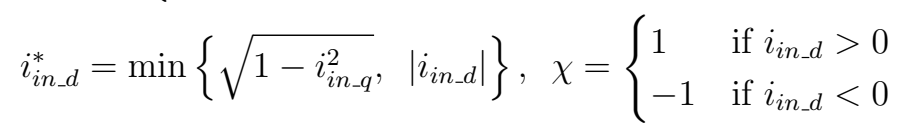




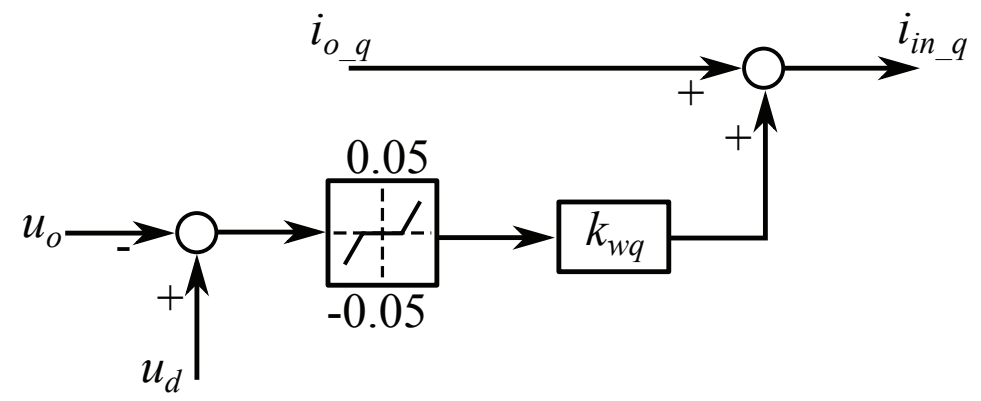

Figure 17: Voltage support control scheme of wind turbine

Table 6: Short circuit control parameter of wind generation units

$$
\begin{aligned}
& \begin{array}{lcc}
\hline \text { Variables } & \text { Value } & \text { Unit } \\
\hline k_{c h} & 9.52 & \text { p.u }
\end{array} \\
& \begin{array}{lll}
k_{w f} & 30 \quad \text { p.u }
\end{array} \\
& k_{w v} \quad 4 \quad \text { p.u } \\
& \begin{array}{lll}
k_{w q} & 5 & \text { p.u }
\end{array} \\
& \omega_{0} \quad 1.0 \quad \text { p.u } \\
& \begin{array}{lll}
u_{0} & 1.0 \quad \text { p.u }
\end{array} \\
& \begin{array}{lll}
P_{\text {limit }} & 0.9 & \text { p.u }
\end{array} \\
& i_{\text {ref-q }}= \begin{cases}\nu \cdot i_{i n_{-} q}^{*} & \text { if }|\underline{u}|>0.8 \wedge|\underline{i}| \geq 1.0 \\
i_{i n_{-} q} & \text { otherwise }\end{cases} \\
& i_{i n_{-} q}^{*}=\min \left\{\sqrt{1-i_{i n_{-}}^{2}},\left|i_{i n_{-} q}\right|\right\}, \nu= \begin{cases}1 & \text { if } i_{i n_{-} q}>0 \\
-1 & \text { if } i_{i n_{-} q}<0\end{cases}
\end{aligned}
$$

Wind generation system no longer controls the DC link as soon as current operational limits are exceeded during fault. The chopper control shown in Fig. 18 is then activated to maintain the DC voltage.

Transient stability of the offshore network during fault is improved with the injection of reactive current by the wind turbine [28]. However, active current must be reduced depending on the network voltage to avoid loss of synchronization. The under-voltage dependent active current reduction scheme is shown in Fig. 19. This scheme also enables the gradual rise in wind energy in-feed during post fault state. 


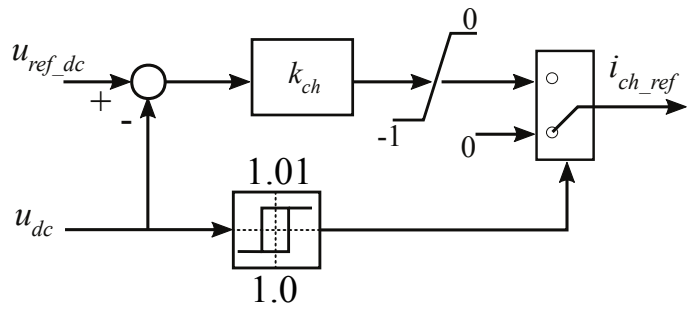

Figure 18: A Chopper control scheme to control DC link of wind generation system during fault

\subsection{Wind Generation Frequency Coordinated Control}

A frequency dependent active current reduction scheme is shown in Fig. 19. Reduction in the active current using integral upper limit, is activated when the system frequency exceeds the upper limit i.e 1.004 p.u. From the view of offshore AC network, the inertia of wind turbines and onshore synchronous generators are isolated due to VSC-HVDC transmission system and fully rated converters of wind generation systems. The frequency on the offshore AC network is directly imposed by the VSC of HVDC transmission system and the imposed frequency relationship with the VSC actual active power is established using droop scheme. The response of the frequency against power change is slow due to low bandwidth of the power measurement filters uses for droop feedback signal. The bandwidth of power measurement filter is limited due to the stability of the offshore AC network [21]. Thus, any sudden change in power in the offshore AC network will largely impact the voltages and the large transient in the voltage is damped by voltage and current control of the converters.

In case, when one export transmission line is disconnected, the voltages in the network will rise faster than the frequency. The rate of change in network frequency depends on the gain of the frequency droop in VSC-HVDC system and it is limited by the stability condition [21]. In the presence of excess energy in the system, the current limit in VSC-HVDC is reached immediately. Consequently, the network reference voltage rises. In the active current reduction scheme shown in Fig. 19, the voltage feed-forward path is added which reduces the active current if network voltage rise above $2 \%$. The rise in voltage will reduces the wind power generation and keeps the net power generation just under the limit of VSC export capacity. Note that as soon as the current flow through VSC-HVDC system try to reduces below the current saturation limit, the voltages in the network try to restore. However, the 

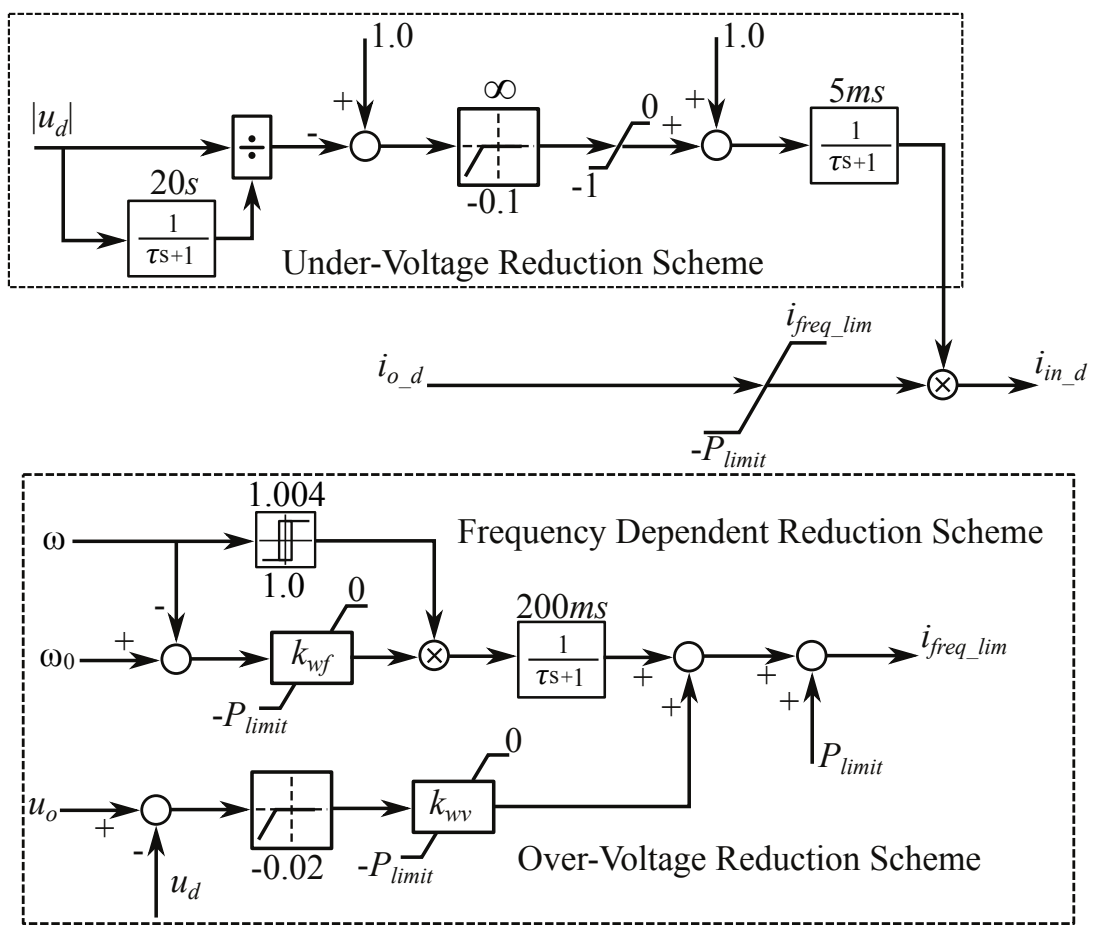

Figure 19: Voltage and frequency dependent active current reduction scheme of wind generation system

reduction in voltage would again increases the wind power generation ergo increases the current through VSC-HVDC system to its limits. At this stage, the voltages in the network would be above the nominal values and power through VSC-HVDC system would be at the saturation limits. The VSC active power above its limit increases the network frequency. Once the measured frequency by the wind generation units reaches the threshold limits. The frequency feed-forward path shown in Fig. 19 reduces the wind power generation. The current through VSC-HVDC system comes back within its limits and reinstates the reference voltage control. The equilibrium in the system will be achieved at reduced wind power generation that would be equal to the export capacity of the transmission line, while keeping network voltages within the operational limits. The per unit change in network frequency 
$(\omega)$ at equilibrium state can be calculated using (13).

$$
\Delta \omega=-\frac{a \cdot\left(\sum_{m=1}^{y} \frac{1}{k_{f \_m}+k_{f s \_m}}\right)^{-1} \sum_{n=1}^{z} P_{\text {limit_n }}}{1+a\left(\sum_{m=1}^{y} \frac{1}{k_{f \_m}+k_{f s \_m}}\right)^{-1} \sum_{n=1}^{z} k_{w f \_n}}
$$

Where; $a=S_{b}^{\text {wind }} / S_{b}^{v s c}$ and it is a ratio of base power of wind generation system and VSC-HVDC, $k_{f_{-} m}$ and $k_{f_{-} m}$ are the frequency droop gains of VSC for normal and disturbance period in p.u respectively, $k_{w f_{-} n}(\mathrm{p} . \mathrm{u})$ is a power reduction gain of wind generation system, $P_{\text {limit_n }}(\mathrm{p} . \mathrm{u})$ is the maximum active power limit of wind generation system, $y$ is the total number of VSCHVDC system, and $z$ is the total number of wind generation system.

\section{Simulations and Results}

The methodology and control system is validated by performing nonlinear simulation of the network shown in Fig. 1. The voltage angle jump phenomena occurs due to change in $X / R$ ratio as discuss in Section. 3. The phase angle jump not only depends on the fault impedance but also on the location of fault. The fault location changes the equivalent impedance as seen from the VSC controlling busbar from its pre-fault state. To observe the network behavior according to the fault location on the network and the effectiveness of the proposed control scheme, four fault locations are considered for the analysis having fault resistance equal to $1 \Omega$. In the network, there are 20 wind turbines each has the 6.0 MW rated active power. The total wind active power in the offshore $\mathrm{AC}$ network is $120 \mathrm{MW}$ which is transferred to two different onshore grids using VSC-HVDC transmission system. The active power transfer capability of each VSC-HVDC system is $100 \mathrm{MW}$.

Fault at $M V$ Busbar. In first case study, a fault is applied at wind turbine (WT-2) MV busbar $(33 \mathrm{kV}$ ). The fault is applied at $5.0 \mathrm{~s}$ and it is removed after $100 \mathrm{~ms}$. All the converters have the fault-ride-through capability (FRT) and they remain connected for $100 \mathrm{~ms}$ and restore its normal operation after fault is removed. The results of the simulation are shown in Fig. 20. The voltage response of both VSCs controlling busbars are shown in Fig. 20a and Fig. 20b. During fault, the voltages drops up to 0.4 p.u. Since the voltages 


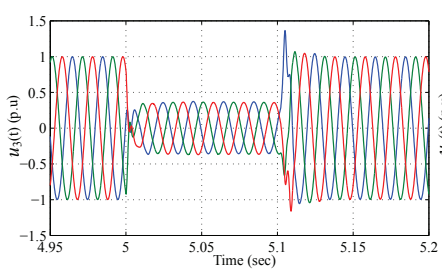

(a) VSC-1 voltage

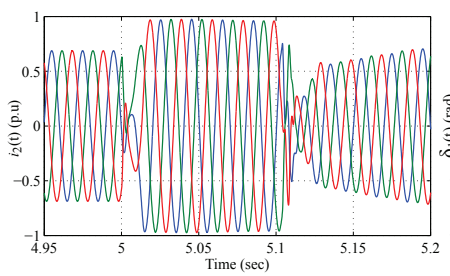

(d) VSC-2 current

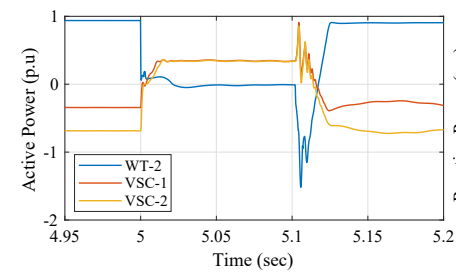

(g) Active power response

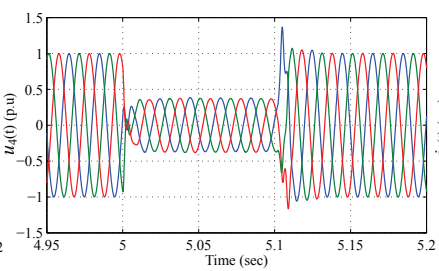

(b) VSC-2 voltage

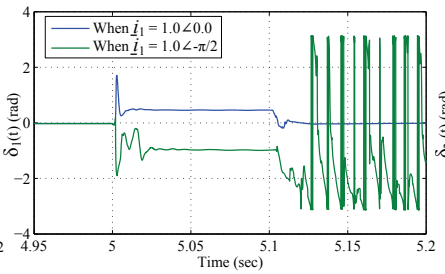

(e) VSC-1 connection bus voltage angle

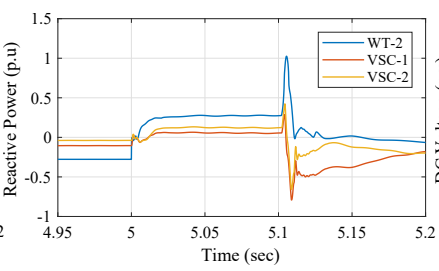

(h) Reactive power response

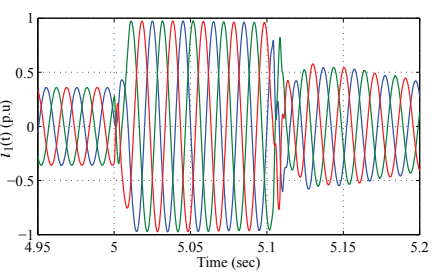

(c) VSC-1 current

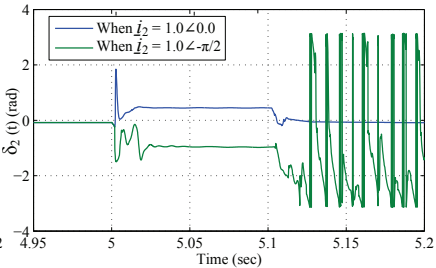

(f) VSC-2 connection bus voltage angle

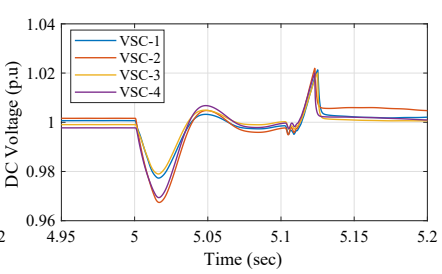

(i) DC voltage response

Figure 20: Short circuit responses of fault at $33 \mathrm{kV}$ wind turbine busbar.

are above the $0.1 \mathrm{p} . \mathrm{u}$, the VSCs injects rated current with the angle of $0.0 \mathrm{rad}$. The current responses of both VSCs are shown in Fig. 20c and Fig. 20d. It is concluded from the previous discussion that VSCs current angle largely impact the voltage phase angle jump during fault period. The comparison of voltage phase angle jump of VSCs connected busbar are shown in Fig. 20e and Fig. 20f. It is clear from the results that the voltage phase angle instability occur during post fault state with the injection of $-\pi / 2 \mathrm{rad}$ VSC current angle. Also, the voltage phase angle during fault and pre-fault state are quite near to each other when VSCs currents are injected with the angle of $0.0 \mathrm{rad}$. Note that all the wind turbines are injecting capacitive reactive current with rated value. The power responses of VSC-HVDC system and WT-2 are shown in Fig. $20 \mathrm{~g}$ and Fig. 20h. All the wind turbines have identical control 


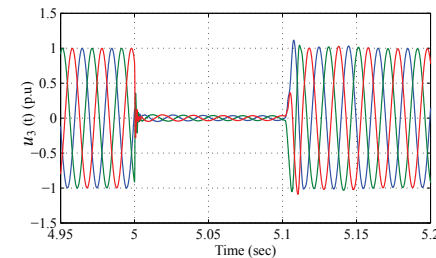

(a) VSC-1 voltage

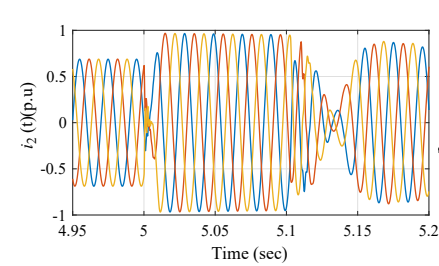

(d) VSC-2 current

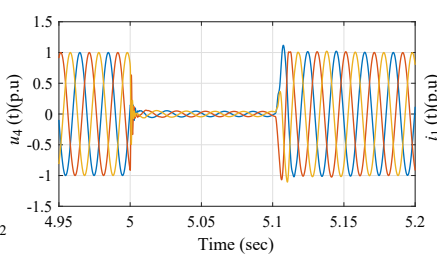

(b) VSC-2 voltage

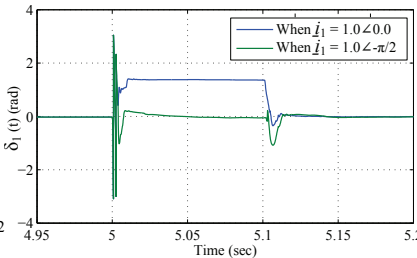

(e) VSC-1 connection bus voltage angle

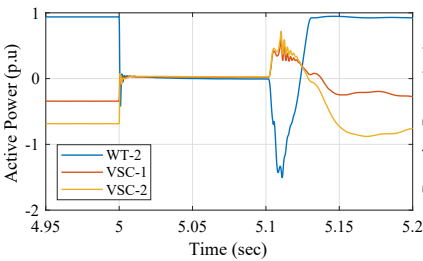

(g) Active power response

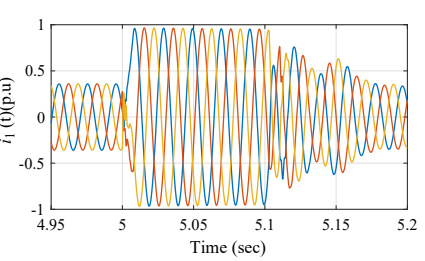

(c) VSC-1 current

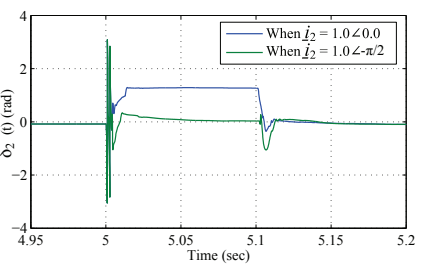

(f) VSC-2 connection bus voltage angle

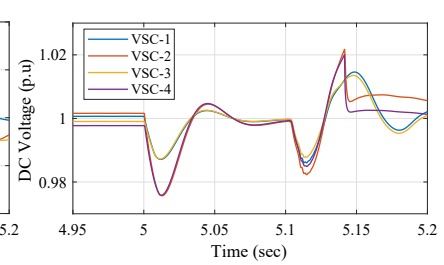

(i) DC voltage response

Figure 21: Short circuit responses of fault at $150 \mathrm{kV}$ busbar.

structure and their behavior are quite similar therefore only the results of WT-2 are shown. Generator oriented sign convention is used i.e + ve sign means that the converters inject the power into the network. Note that the active power are injected by the VSCs during fault period which are supplied by the onshore grid. The change in the power flow impacts the DC voltages which can be observed from Fig. 20i, however the DC voltage deviations are within the operating range at both end of the cable i.e offshore and onshore.

Fault at $H V$ Busbar. In the second case study, the fault is applied at the transformer busbar at $150 \mathrm{kV}$. The condition of the fault is same as in previous case study. The simulation results of this case study are shown in Fig. 21. The fault at the HV busbar is relatively close to VSC-HVDC system which 
reduces the VSC controlling busbar voltages to 0.05 p.u. The voltage responses are shown in Fig. 21a and Fig. 21b. Since the voltages drop below $0.1 \mathrm{p} . \mathrm{u}$, the VSCs injects current with the angle of $-\pi / 2 \mathrm{rad}$. The response of VSC currents are shown in Fig. 21c and Fig. 21d. Furthermore in order to validate the proposed control scheme, the comparison of voltage phase angle of VSCs connecting busbars are shown in Fig. 21e and Fig. 21f. It is clear from the results that the pre-fault and fault voltage phase angle are same with $-\pi / 2$ current angle infeed by the VSCs. This not only improves the transient response as well as no active power is supplied by the onshore grids into the offshore AC network during fault period as shown in Fig. 21g. The power response shows some initial large transient during recovery period due to unbalance voltages and current response. The proposed control scheme successfully damped those transients and the network continue its operation. The responses of DC voltages are shown in Fig. 21i which indicates that the voltages are within in operational limits.

Fault at HVAC Cable. In third case study, the ability of the VSC-HVDC system to operate two isolated offshore AC network has been demonstrated. The response of the simulation is shown in Fig. 22. In this analysis, a permanent fault is applied on the middle of HVAC cable which connects VSC-1 substation with VSC-2 substation. The length of this cable is $12 \mathrm{~km}$. The fault is applied at $5.0 \mathrm{~s}$ and it is isolated by opening the $\mathrm{AC}$ circuit breakers at both end of the cable after $100 \mathrm{~ms}$. The voltage responses of the VSCs controlling busbars are shown in Fig. 22a and Fig. 22b. During fault, the voltages drops to $0.04 \mathrm{p} . \mathrm{u}$ and the VSCs injects the rated current with the angle of $-\pi / 2 \mathrm{rad}$. The VSCs current responses are shown in Fig. 22c and Fig. 22d. In the pre-fault state, $33.3 \%$ of total wind power is transferred to country-A through VSC-1 and $66.7 \%$ is transferred to country-B through VSC-2. Note that the frequencies imposed by both offshore VSCs i.e VSC-1 and VSC-2 are converged at the same steady state value as illustrated in Fig. 22e. Two isolated offshore AC network are formed after fault isolation. After fault isolation, the wind power plants 1 and 2 are now connected with VSC- 1 only, and wind power plant 3 is connect with VSC-2 only. The frequencies of both offshore $\mathrm{AC}$ network are now different which depends on the frequency droop value of the respective converters. Note that the export power of VSC-1 has now increased which is equal to the combined power of wind power plants 1 and 2 nevertheless the combined power is lower than the rated power of VSC-1. In post fault state, 0.8 p.u active power flow through 


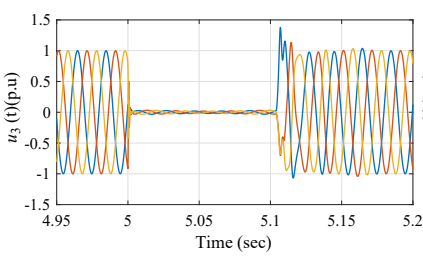

(a) VSC-1 voltage

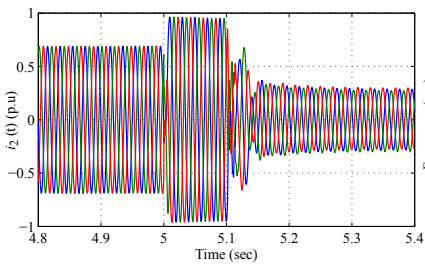

(d) VSC-2 current

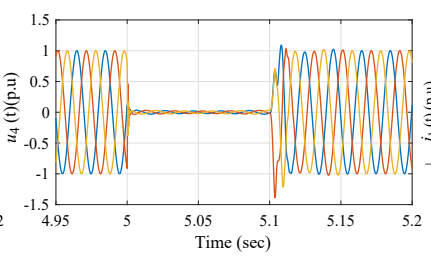

(b) VSC-2 voltage

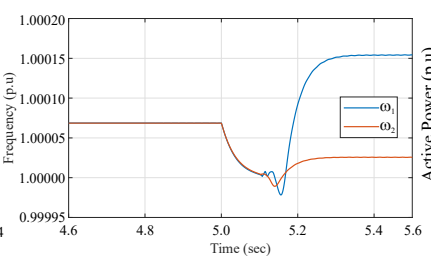

(e) Frequency response

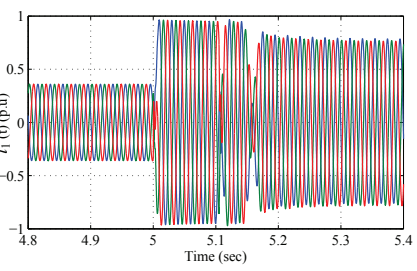

(c) VSC-1 current

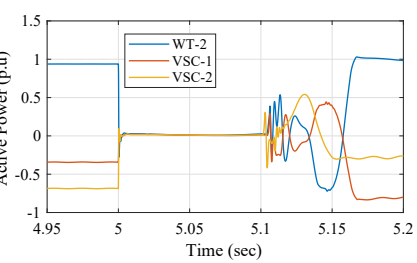

(f) Active power response

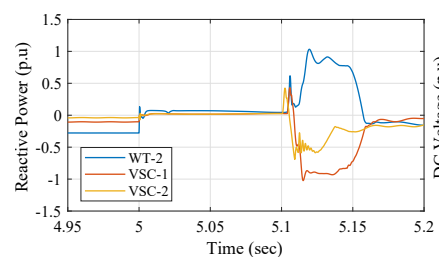

(g) Reactive power response

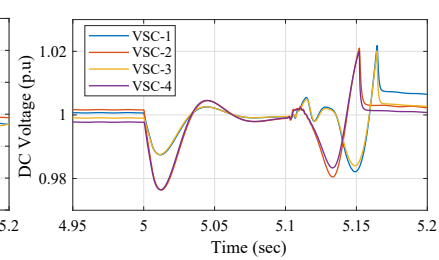

(h) DC voltage response

Figure 22: Short circuit response of fault on HVAC cable between VSC 1 and 2 substation.

VSC-1 and 0.27 p.u flows through VSC-2. The active and reactive power responses are shown in Fig. $22 \mathrm{f}$ and Fig. 22g. The transient during recovery period appear due to change in the networks frequencies and change in local references. The DC voltage response of VSC-HVDC systems are shown in Fig. 22h. The post-fault DC voltage variations are different in both DC cables due to difference in active power flow nevertheless the onshore converter maintain the DC voltage within the limits.

VSC-2 Open Circuit Fault. In the fourth case study, the frequency coordinated control scheme of wind generation units and VSC-HVDC transmission systems has been analyzed. The responses of this simulation are shown in Fig. 23. The frequency coordinated control scheme is validated by opening the AC circuit breaker of VSC-2 at $15 \mathrm{~s}$. The combined active power generation of wind power plants is $120 \mathrm{MW}$ which is greater than VSC-1 rated 


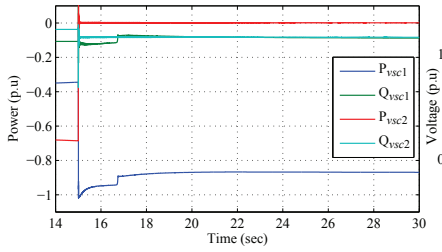

(a) Power response

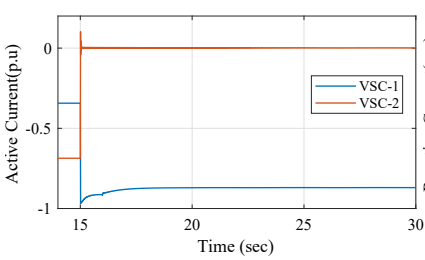

(d) Current d-axis response

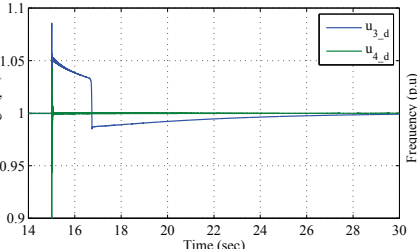

(b) Voltage response

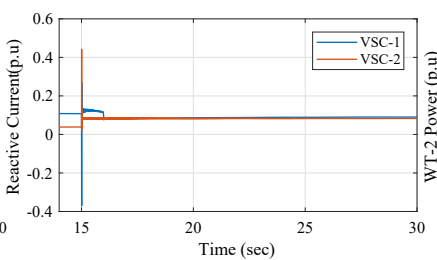

(e) Current q-axis response

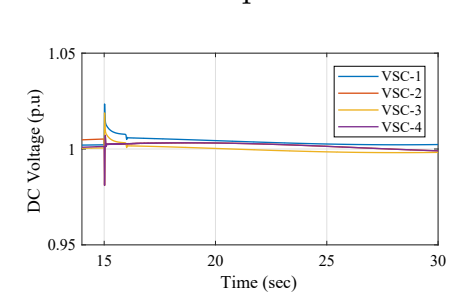

(g) DC voltage response

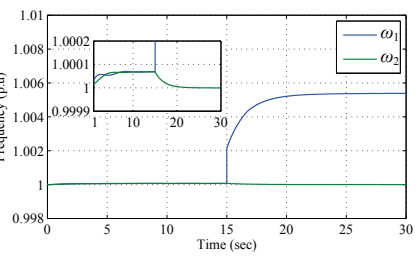

(c) Frequency response

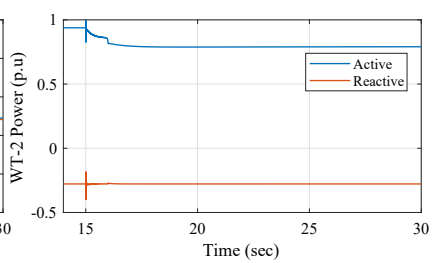

(f) Wind power response

(g) DC voltage response

Figure 23: VSC-2 substation disconnection response of the network.

power. Thus, wind generation units need to reduce their power generation according to the capacity of VSC-1. The power response of the VSC-1 and VSC-2 is shown in Fig. 23a. Note that the VSC-2 is only disconnected from the offshore AC network in the simulation from the transformer end at $150 \mathrm{kV}$ level. The active power flow through VSC-2 is zero after $15 \mathrm{~s}$ and it received the reactive power due to the filter capacitor connected at its controlling busbar. The active power of VSC-1 suddenly reaches its power and current limits consequently rise the offshore $\mathrm{AC}$ network voltages. The response of VSC-1 and VSC-2 controlling busbar are shown in Fig. 23b. The voltage rises up to $1.05 \mathrm{p} . \mathrm{u}$ in the network. This rise in voltage activate the voltage dependent active current reduction scheme in the wind generation units consequently reduces the wind power generation. The rise in offshore frequency is slow compared to the rise in the voltage which can be seen from the frequency response shown in Fig. 23c. During the time period between 15 to 
17 second, the wind active power is reduced due to over voltages in the network. After $17 \mathrm{~s}$, the over frequency activate the frequency dependent active current reduction scheme which further reduces the wind power generation. Once the current in the VSC reaches under its limits as shown in Fig. 23d and Fig. 23e, VSC reinstate the voltage control and maintain the offshore AC network voltages near nominal values. The voltage dependent active current reduction scheme in the wind generation units become deactivated, and the reduction in the power is based on the frequency of the network. The power response of the WT-2 is shown in Fig. 23f. The change in the offshore AC network power flow has minimum effects on the DC voltages as shown in Fig. 23g and the onshore converters show robust performance to maintain the $\mathrm{DC}$ voltage at the nominal value.

\section{Conclusion}

The article presents the control system of the VSC-HVDC system for an offshore AC network for normal and short circuit operation. The offshore AC network is created by two VSCs using frequency and voltage droop control schemes. During short circuit, both VSCs are injecting current up to their maximum capability. It has been concluded that VSCs must inject active current for not so low fault voltage to ensure the voltage angle stability during fault and post fault state. Furthermore, reactive current injection by the VSCs improves the network voltages for low voltage fault and keeps the network bus voltage angle near to pre-fault state. Through simulation, it has been proven that the control of the offshore AC network reference voltage and frequency via more than one VSC-HVDC system provides operational redundancy, and network can still be operated if isolation occurs between VSC-HVDC systems. Furthermore, the proposed coordinated control ensures continuous operation of the network at reduced export capacity. The presented study and proposed control system can be a useful tool for establishing offshore grid codes.

\section{Acknowledgments}

The research leading to these results has received funding from the People Programme (Marie Curie Actions) of the European Unions Seventh Framework Programme (FP7/2007-2013) under REA grant agreement n317221. 


\section{References}

[1] P. Sandeberg, P. Moran, A. Lomardi, A. Hernandez, C. Feltes, D. Ramsay, Special considerations for ac collector systems and substations associated with hvdc connected wind power plants, Tech. Rep. March, CIGRE WG B3.36 (2015).

[2] C. Humpert, Long distance transmission systems for the future electricity supply Analysis of possibilities and restrictions, Energy 48 (1) (2012) 278-283. doi:10.1016/j.energy.2012.06.018.

[3] J. I. Marvik, H. G. Svendsen, Analysis of Grid Faults in Offshore Wind Farm with HVDC Connection, Energy Procedia 35 (2013) 8190. doi:10.1016/j.egypro.2013.07.161.

[4] R. A. Walling, E. Gursoy, B. English, Current contributions from Type 3 and Type 4 wind turbine generators during faults, in: 2011 IEEE Power and Energy Society General Meeting, IEEE, 2011, pp. 1-6. doi:10.1109/PES.2011.6039740.

[5] Tennet TSO GmbH, Requirements for Offshore Grid Connections in the Grid of TenneT TSO GmbH (2012).

URL http://www.tennet.eu/de/en/customers/grid-customers/ grid-connection-regulations.html

[6] A. A. van der Meer, M. Ndreko, M. Gibescu, M. A. M. M. van der Meijden, The Effect of FRT Behavior of VSC-HVDCConnected Offshore Wind Power Plants on AC/DC System Dynamics, IEEE Transactions on Power Delivery 31 (2) (2016) 878-887. doi:10.1109/TPWRD.2015.2442512.

[7] M. Aragues Penalba, O. Gomis-Bellmunt, M. Martins, Coordinated Control for an Offshore Wind Power Plant to Provide Fault Ride Through Capability, IEEE Transactions on Sustainable Energy 5 (4) (2014) 1253-1261. doi:10.1109/TSTE.2014.2344172.

URL http://ieeexplore.ieee.org/lpdocs/epic03/wrapper.htm? arnumber $=6895151$

[8] O. Goksu, R. Teodorescu, C. L. Bak, F. Iov, P. C. Kjaer, Instability of Wind Turbine Converters During Current Injection to Low 
Voltage Grid Faults and PLL Frequency Based Stability Solution, IEEE Transactions on Power Systems 29 (4) (2014) 1683-1691. doi:10.1109/TPWRS.2013.2295261.

URL http://ieeexplore.ieee.org/articleDetails.jsp? arnumber $=6704843$

[9] C. Feltes, H. Wrede, F. W. Koch, I. Erlich, Enhanced fault ride through method for wind farms connected to the grid through vsc based hvdc transmission, IEEE Transactions on Power Systems 24 (3) (2009) 1537-1546. doi:10.1109/TPWRS.2009.2023264.

URL http://ieeexplore.ieee.org/lpdocs/epic03/wrapper.htm? arnumber=5170211http: //ieeexplore . ieee. org/articleDetails . jsp?arnumber $=5170211$

[10] Y. Liu, Z. Chen, A Flexible Power Control Method of VSC-HVDC Link for the Enhancement of Effective Short-Circuit Ratio in a Hybrid Multi-Infeed HVDC System, IEEE Transactions on Power Systems 28 (2) (2013) 1568-1581. doi:10.1109/TPWRS.2012.2222057.

URL http://ieeexplore.ieee.org/lpdocs/epic03/wrapper.htm? arnumber $=6341872$

[11] M. Ndreko, M. Popov, M. A. van der Meijden, Study on FRT compliance of VSC-HVDC connected offshore wind plants during AC faults including requirements for the negative sequence current control, International Journal of Electrical Power \& Energy Systems 85 (2017) 97-116. doi:10.1016/j.ijepes.2016.08.009.

URL http://www.sciencedirect.com/science/article/pii/ S014206151630758X

[12] O. Giddani, A. Y. Abbas, G. P. Adam, O. Anaya-Lara, K. Lo, Multitask control for VSCHVDC power and frequency control, International Journal of Electrical Power \& Energy Systems 53 (2013) 684-690. doi:10.1016/j.ijepes.2013.05.002.

URL http://linkinghub.elsevier.com/retrieve/pii/ S0142061513001944

[13] I. Erlich, C. Feltes, F. Shewarega, Enhanced voltage drop control by vsc hvdc systems for improving wind farm fault ride through capability, IEEE Transactions on Power Delivery 29 (1) (2014) 378-385. 
doi:10.1109/TPWRD.2013.2285236.

URL http://ieeexplore.ieee.org/lpdocs/epic03/wrapper.htm? arnumber $=6685932$

[14] B. Weise, Impact of K-factor and active current reduction during faultride-through of generating units connected via voltage-sourced converters on power system stability, IET Renewable Power Generation 9 (1) (2015) 25-36. doi:10.1049/iet-rpg.2014.0116.

URL http://digital-library.theiet.org/content/journals/10. 1049/iet-rpg. 2014.0116

[15] E.-C. Nho, J.-H. Jung, I.-D. Kim, T.-W. Chun, H.-G. Kim, N.S. Choi, J. Choi, Voltage disturbance generator with phase jump for the test of microgrid, in: The 2010 International Power Electronics Conference - ECCE ASIA -, IEEE, 2010, pp. 487-491. doi:10.1109/IPEC.2010.5543505.

URL http://ieeexplore.ieee.org/document/5543505/

[16] M. Mohseni, S. M. Islam, M. A. S. Masoum, Impacts of Symmetrical and Asymmetrical Voltage Sags on DFIG-Based Wind Turbines Considering Phase-Angle Jump, Voltage Recovery, and Sag Parameters, IEEE Transactions on Power Electronics 26 (5) (2011) 1587-1598. doi:10.1109/TPEL.2010.2087771.

URL http://ieeexplore.ieee.org/document/5604703/

[17] W. Wang, N. Chen, L. Zhu, D. Xu, Phase angle compensation control strategy for low voltage ride through of doubly-fed induction generator, in: 2009 International Conference on Sustainable Power Generation and Supply, IEEE, 2009, pp. 1-7. doi:10.1109/SUPERGEN.2009.5348205.

URL http://ieeexplore. ieee.org/document/5348205/

[18] J. D. Deckar, P. Kreutzkamp, Offshore Electricity Grid Infrastructure in Europe: A Techno-Economic Assessment, Tech. rep., OffshoreGrid (3E Coordinator), Brussels (oct 2011).

URL http://www. offshoregrid.eu/

[19] M. Raza, K. Schönleber, O. Gomis-Bellmunt, Droop Control Design of Multi-VSC Systems for Offshore Networks to Integrate Wind Energy, Energies 9 (10) (2016) 826. doi:10.3390/en9100826.

URL http://www.mdpi . com/1996-1073/9/10/826/htm 
[20] X. Hu, J. Liang, D. J. Rogers, Y. Li, Power Flow and Power Reduction Control Using Variable Frequency of Offshore AC Grids, IEEE Transactions on Power Systems 28 (4) (2013) 3897-3905. doi:10.1109/TPWRS.2013.2257884.

[21] M. Raza, E. Prieto-Araujo, O. Gomis-Bellmunt, Small Signal Stability Analysis of Offshore AC Network having Multiple VSC-HVDC System, IEEE Transactions on Power Deliverydoi:10.1109/TPWRD.2017.2725982.

[22] Nexans, Nexans Submarine Power Cables (2013).

URL http://www. nexans.de

[23] ABB, XLPE submarine cable systems.

URL http://new.abb.com/cables/cables/hvac-extruded-cables/ hvac-submarine-cables

[24] J. Schlabbach, K. Heinz Rofalski, Transformers, in: Power System Engineering: Planning, Design, and Operation of Power Systems and Equipment, Wiley-VCH Verlag GmbG \& Co. KGaA, 2008, Ch. 7, pp. 81-110.

[25] J. Glasdam, J. Hjerrild, L. H. Kocewiak, C. L. Bak, Review on multilevel voltage source converter based HVDC technologies for grid connection of large offshore wind farms, in: 2012 IEEE International Conference on Power System Technology (POWERCON), IEEE, 2012, pp. 1-6. doi:10.1109/PowerCon.2012.6401377.

[26] N.-T. Trinh, M. Zeller, K. Wuerflinger, I. Erlich, Generic Model of MMC-VSC-HVDC for Interaction Study With AC Power System, IEEE Transactions on Power Systems 31 (1) (2016) 27-34. doi:10.1109/TPWRS.2015.2390416.

[27] M. Raza, O. Gomis-Bellmunt, Control design strategy to enhance fault right through capability of vsc hvdc transmission system interconnecting offshore wind power plant, in: European Wind Energy Association Annual Conference EWEA 2015, EWEA, Paris, 2015, pp. 1-9.

URL http://www.ewea.org/annual2015/conference/programme/ info2 $\cdot$ php?id2 $=1125$

[28] I. Erlich, F. Shewarega, S. Engelhardt, J. Kretschmann, J. Fortmann, F. Koch, Effect of wind turbine output current during faults on grid 
voltage and the transient stability of wind parks, in: 2009 IEEE Power \& Energy Society General Meeting, IEEE, 2009, pp. 1-8. doi:10.1109/PES.2009.5275626.

URL http://ieeexplore.ieee.org/lpdocs/epic03/wrapper.htm? arnumber $=5275626$ 